\title{
Summary of Literature Review of Risk Communication - Hanford Environmental Dose Reconstruction Project
}

\section{S. J. Byram}

May 1991
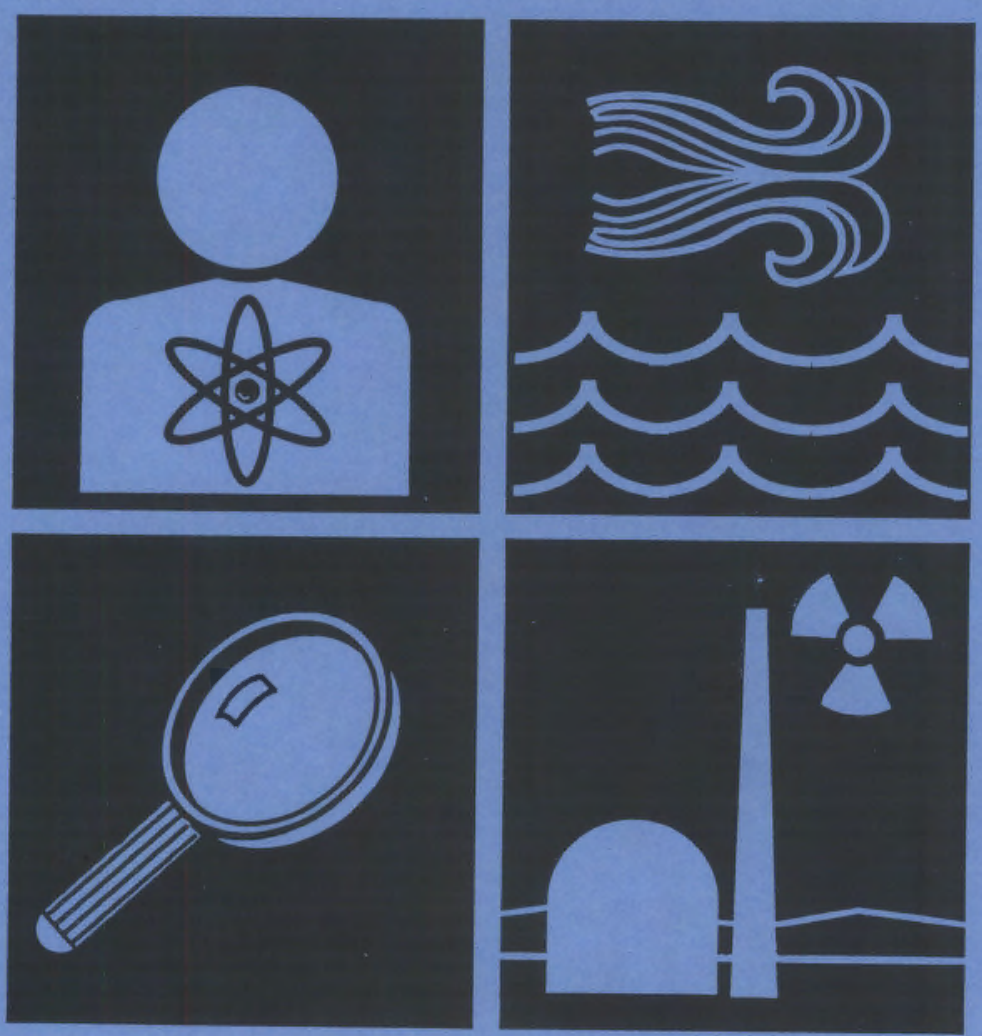

Prepared for the Technical Steering Panel 


\section{DISCLAIMER}

This report was prepared under the direction of the HANFORD ENVIRONMENTAL DOSE RECONSTRUCTION PROJECT Technical Steering Panel by Battelle Memorial Institute's Pacific Northwest Laboratories operating the Pacific Northwest Laboratory for the U.S. Department of Energy (DOE). While funding for the work was provided by DOE, the work is not under DOE direction or control. The views and opinions of the authors expressed in this document do not necessarily reflect those of the United States Government or any agency thereof. Reference herein to any specific commercial product, process or service by trade name, trademark, manufacturer or otherwise does not necessarily constitute or imply its endorsement, recommendation or favoring by the U.S. Government or any agency thereof, nor by Battelle Memorial Institute.

Printed in the United States of America

Available to DOE and DOE contractors from the

Office of Scientific and Technical Information, P.O. Box 62, Oak Ridge, TN 37031 ; prices available from (615) 576-8401. FTS 626-8401.

Available to the public from the National Technical Information Service, U.S. Department of Commerce, 528S Port Royal Rd., Springfield, VA 22161. 
SUMMARY OF LITERATURE REVIEW OF RISK COMMUNICATION - HANFORD ENVIRONMENTAL DOSE RECONSTRUCTION PROJECT

S. J. Byram

May 1991

Prepared for

the Technical Steering Panel

Pacific Northwest Laboratory Richland, Washington 99352 


\section{SUMMARY OF LITERATURE REVIEW OF RISK COMMUNICATION - HANFORD ENVIRONMENTAL DOSE RECONSTRUCTION PROJECT}

May 1991

This document has been reviewed and approved by the Technical Steering Panel.

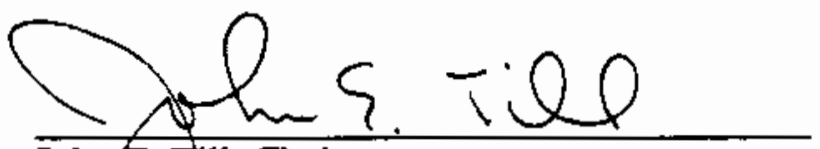

Johr/E. Till, Chairman

Technical Steering Panel

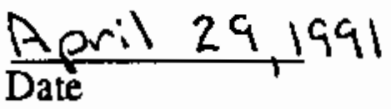

Hanford Environmental

Dose Reconstruction Project 
FOREWORD

Responding to TSP Directive $89-7$

In May 1989, the Technical Steering Panel issued Directive 89-7, "Presentation of Technical Material to the Public." That directive required HEDR staff at PNL to examine methods to comnunicate the causes and effects of uncertainties in the dose estimates. Specifically, it asked staff to

- investigate methods for presenting to the lay public information about uncertainties in dose estimates

- review past examples of communication of technical information to lay audiences

- seek out and consider innovative methods for such communication.

These activities were to be documented, including descriptions of communication methods and an evaluation of each method's cost and effectiveness.

HEDR staff undertook a broad interpretation of this directive to include all project communication, not just the communication of dose uncertainties. Several key materials document HEDR staff work in fulfilling this directive:

- "Sumnary of Literature Review on Risk Communication - Hanford Environmental Dose Reconstruction Project," by S. J. Byram, PNL-7226 HEDR. This report summarizes risk communication principles as presented in existing literature.

- "A Preliminary Examination of Audience-Related Communications Issues for the Hanford Environmental Dose Reconstruction Project," by C. W. Holmes, PNL-723] HEDR. This report summarizes the results of focus group discussions held throughout Washington state, briefly analyzes media content of TSP meetings, summarizes results of Hanford-related surveys done by others, and presents issues and recommendations for TSP consideration in future communications efforts.

- "Comunications Directive" by R. E. Rhoads, PNL-SA-17903 S HEDR. This packet of viewgraphs shown at the February 1990 TSP meeting highlights key points in the oral presentation given by $R$. $E$. Rhoads. The presentation included a review of HEDR work to date in carrying out the TSP directive, a summary of the audience analysis results, suggested communication mechanisms, and recommended communications objectives. 
General cost estimates for various communication activities were provided in informal meeting notes and other verbal discussions with members of the TSP Communications Subcommittee. Costs for communication methods the TSP has used to date can be found in TSP reports on public communication and involvement activities and in other materials produced by the TSP. Cost estimates for proposed activities are developed by PNL as input to the TSP Communications Subcommittee planning and budgeting activities by fiscal year. Putting Recent TSP Communication Developments in Context

This report was provided in draft form to the TSP in December 1989. Therefore, some of the "upcoming" work referred to in this report has already occurred. In addition, much of the report contains suggested guidelines recommended for the TSP's public communication activities. Since the time this report was first made available, the TSP has expanded and modified its public communication program, including applying many of the suggested guidelines presented herein.

\section{Addressing TSP Comments}

Appendix $D$ is a record of TSP comments and Battelle's responses to those comments; the TSP has reviewed and approved 8attelle's responses. Comment numbers appear in this report in the left margin next to the paragraphs in which the corresponding comments were addressed. Changed text is shown in italics. 


\section{SUMMARY}

The Hanford Environmental Dose Reconstruction (HEDR) Project will estimate radiation exposures people may have received from radioactive materials released during past operations at the Department of Energy's Hanford Site near Richland, Washington. The project is being conducted by Pacific Northwest Laboratory (PNL) under the direction of an independent Technical Steering Panel (TSP). The Centers for Disease Control (CDC) will use HEDR dose estimates in studies to investigate a potential Tink between thyroid disease and historical Hanford emissions.

The HEDR Project was initiated to address public concerns about the possible health impacts from past releases of radioactive materials from Hanford. The TSP recognized early in the project that special mechanisms would be required to communicate effectively to the many different concerned audiences. To identify and develop these mechanisms, the TSP issued Directive 89-7 to PNL in May 1989. The TSP directed PNL to examine methods to communicate the causes and effects of uncertainties in the dose estimates.

After considering the directive and discussing it with the Communications Subcommittee of the TSP, PNL undertook a broad investigation of communications methods for project applications. At the TSP's February 1990 meeting, PNL will recommend strategies and mechanisms to meet the project communications objectives.

A literature review was conducted as the first activity in response to the TSP's directive. This report presents the results of the literature review. The objective of the literature review was to identify "key principles" that could be applied to develop communications strategies for the project. The key principles identified include the following:

- Convey consistent and accurate information. Credibility can be built and maintained only if all speakers know, understand, and convey the same message. Coordinated efforts among the TSP, CDC and PNL will be required to follow this principle in the HEDR Project. 
- Develop and adhere to clear communications objectives. Communicating with people about health issues is difficult. The starting point in a successful communication process is to clearly define the communication objectives. Communication must be consistent with these objectives to establish credibility, to clarify expectations, and to reduce unnecessary conflict.

- Establish early dialogue to understand the needs of the audience. Communications will be successful only if they address the concerns of the people receiving the information. The only way to clearly understand these concerns is to have effective dialogue, a two-way exchange, with the audience. Each audience must be treated on its own terms.

- Recognize and deal with outrage. People deal with health issues on an emotional level. Communications must identify, understand, and respond to qualitative concerns as well as to the science.

- Pay attention to the process. Credibility will depend on an open, honest, and consistent communication process. Good communication starts early and continues through each step of the project. A proper balance must be achieved between openness, accuracy, and interpretation.

- Dea1 directly with uncertainty. The 1 imitations in the research must be acknowledged. People must be helped to understand the effort expended to be complete and accurate. Communicators should explain that cautious analysis is used when there is uncertainty. The focus should be on the effects of uncertainties on the research conclusions and their sensitivities.

- HeTp people understand the risks. People are very "bottom line" oriented in studies dealing with health issues. They want to know if they were harmed. HEDR results must be presented in such a way that they help people address these basic concerns.

- Incorporate feedback and evaluation. A successful communication program will learn from its successes and deficiencies. 


\section{CONTENTS}

FOREHORD ...............................

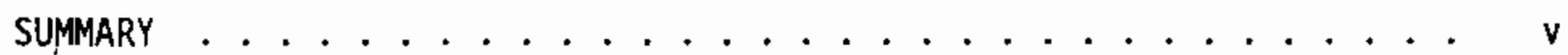

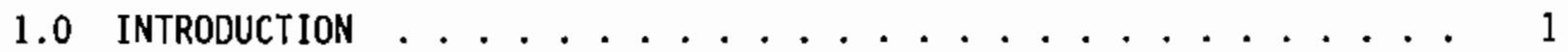

2.0 OVERVIEW OF THE LITERATURE ............... 3

3.0 THE COMMUNICATION PROCESS ............... 5

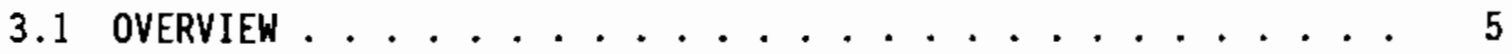

3.2 COMMUNICATION OBJECTIVES . . . . . . . . . . 6

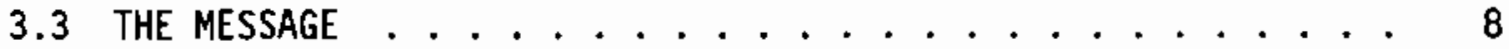

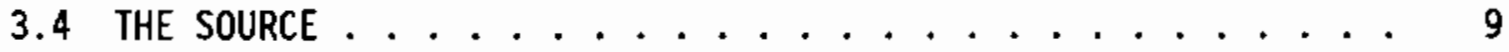

3.5 THE CHANNELS ........................ 11

3.6 THE AUDIENCE . . . . . . . . . . . . . . . . 12

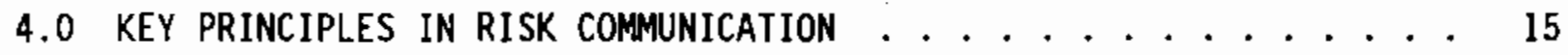

4.1 KNOW AND UNDERSTAND YOUR MESSAGE ............. 15

4.2 KNOW YOUR OBJECTIVE ...................... 16

4.3 KNOW YOUR AUDIENCE AND ESTABLISH DIALOGUE EARLY . . . . . 17

4.4 BE AWARE OF OUTRAGE FACTORS .................... 19

4.5 PAY ATtention tO THE PROCESS. . . . . . . . . . . 20

4.6 DEAL DIRECTLY WITH UNCERTAINTY . . . . . . . . . . 23

4.7 EXPLAINING RISK . . . . . . . . . . . . 25

4.8 FEEDBACK AND EVALUATION . . . . . . . . . . 28

REFERENCES ............................. 31

BlBLIOGRAPHY ......................... 33

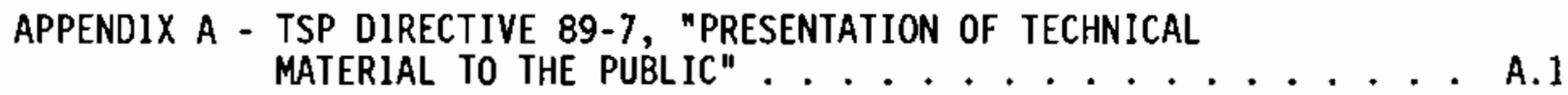

APPENDIX B - ANNOTATED BIBLIOGRAPHY .............. B. . . . 
APPENDIX C - METHODS FOR EXPLAINING TECHNICAL INFORMATION . . . . . . c.l APPENDIX D - SUMMARY OF TSP COMMENTS AND BATTELLE RESPONSES . . . . . . D.I 


\section{FIGURES}

3.1 The Communications Procesș . . . . . . . . . . . 6

3.2 Checklist for a Complete Message ............. 10

C.l The Causal Model ................. C.l

C.2 The Fault Tree ................ C.2

C.3 The Materials and Energy Flow Diagram ........... C.3

C.4 The Risk Analysis Checklist ............... C.4 


\subsection{INTRODUCTION}

The Hanford Environmental Dose Reconstruction (HEDR) Project is estimating radiation doses from past operations at the U.S. Department of Energy's (DOE's) Hanford Site near Richland, Washington. The project was initiated in response to public concerns about potential health effects from Hanford operations. Releases of radioactive material from the Hanford Site began in 1944. The largest releases to the atmosphere occurred between 1944 and 1947. The largest releases to the Columbia River occurred in the late 1950 s and early 1960s.

The HEDR Project is conducted by staff at the Pacific Northwest Laboratory (PNL) under the direction of an independent Technical Steering Panel (TSP). The TSP makes major project decisions and reviews, evaluates, and approves all project reports. The DOE funds the work but provides no technical direction or oversight.

The TSP recognized a major project challenge is the need to communicate to people. A broad range of people are interested in the project results, from people who lived near Hanford at the time of the releases to state and federal agencies to public interest groups. Because of this broad range of audiences and the technical complexity of the research, the TSP and project staff recognized that special mechanisms would be required to communicate effectively. To initiate the process of developing this information, the TSP issued Directive 89-7 on May 20, 1989 (Appendix A). The directive instructed HEDR staff to investigate methods for presenting information to the public about the causes and magnitudes of uncertainties in dose estimates.

After reviewing and discussing the directive with the TSP Communications Subcommittee, project staff undertook a broad investigation of communications mechanisms. While uncertainty is an important aspect of the communications challenge, there are many other challenges that must be addressed. At the end of this work, the project staff will recommend communications strategies and mechanisms that could be used to meet the communications objectives of the project. 
Several activities are being pursued to respond to these challenges to meet the directive of the TSP. These include

- working with the Communications Subcommittee to define communications objectives for the project

- reviewing the literature on communicating health and safety risk information to the public

- analyzing the concerns and information needs of the various groups of people who may use the results of the dose reconstruction project

- assessing mechanisms that can be used to effectively communicate project results through the media

- evaluating communications mechanisms and developing recommendations to the TSP. Final recommendations will be delivered to the TSP at their meeting in February, 1990.

This report contains the results of the literature review. The objective was to extract a set of "guiding principles" that could be used to develop effective communications strategies for the HEDR Project. The process of relating the information in the literature to the HEDR Project situation was not straightforward. Some of the 1 iterature describes theories that seem applicable, but few of these theories have been tested. Some of the literature discusses case studies that have similarities with HEDR, but there were no good matches. Theory had to be blended with practical experience to develop a baseline of sound concepts. Most of this report is devoted to describing these concepts. Section 2.0 presents an overview of the literature. Section 3.0 presents an overview discussion of the communications process to provide the reader with background information. Communications principles are presented in Section 4.0 . 


\subsection{OVERVIEW OF THE LITERATURE}

The literature review was initiated with a computer search of 15 literature databases, using key words such as risk communication, risk perception, public involvement, and radiation. This search yielded approximately 140 possible selections. About 35 were chosen for detailed review based on database-provided summaries, abstracts, and titles. 0ther potentially useful materials were identified through informal contacts with scientists working in the risk communication field. After learning of the HEDR Project, researchers usually shared available information. About 110 documents were identified through this mechanism. Approximateiy 35 of these were determined to be relevant to the HEDR Project and reviewed in detail.

An annotated bibliography was developed for the 70 books, journal articles, conference papers and technical reports judged to be potentially relevant to the HEDR Project. The annotated bibliography does not summarize each and every document. Rather, the selected abstracts are intended to add depth, relevance, and perspective to this report. The annotated bibliography is in Appendix B.

The major topics covered in the literature review included technical risk analysis and communication (63\% of the items reviewed), risk perception (18\%), principles of public involvement (13\%), and health communication (6\%). of these, $39 \%$ were theoretical in nature, $27 \%$ anecdotal, $26 \%$ empirical, and $8 \%$ were case studies. An item was considered theoretical if it was based on substantial scientific evidence, but was not empirically proven. Many of the technical risk analysis and communication documents were theoretical in nature. An anecdotal item was based on experience, lessons learned, and common sense but with fewer scientific references. Empirical studies usually involved controlled experiments to test a particular hypothesis. Most of the empirical studies dealt with risk perception. A few addressed technical risk analysis and communication (e.g., development of risk comparisons). 


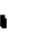




\subsection{THE COMMUNICATION PROCESS}

Communicating with the public about health and safety issues is an interactive process of exchanging information between individuals, groups, and institutions. Multiple messages are involved about the nature of risk, and about concerns, opinions, and reactions to risk (National Research Council 1989). Successful risk communication is not getting someone to agree with our decisions or judgments; rather, successful risk communication enables the members of the audience to make their own informed judgments, regardless of agreement (Chess 1987).

In the past, the public allowed government, industry, and scientific experts to manage, regulate, and protect public health and safety and national resources. However, as perceived abuses of this power have surfaced (e.g., the Vietnam war, Watergate, Love Canal, Three Mile Island), the public has chosen to participate more actively in the political management and regulatory processes. The success of this process depends on an effective communication process. Understanding the process can help us recognize why communication efforts fail or succeed. More importantly, a conscious effort in planning for each element can result in a better risk communication process. The major pieces of the communication process are described in this section. Key principles to help the process work effectively are summarized in Section 4.0 .

\subsection{OVERVIEW}

The communication process has five elements: the objective, the message (what is being said), the source (who is saying it), the channel (the method of communication), and the receiver (the audience). The relationship among these elements is depicted in Figure 3.1. The process starts and ends with the audience. The information needs of the audience determine the communications objectives. The project results are packaged into messages that achieve these objectives. The message will travel to different segments of the audience through different communications channels. An appropriate source and communication technique must be used to assure that the message is

received accurately through each channel. Regular feedback and evaluation is 


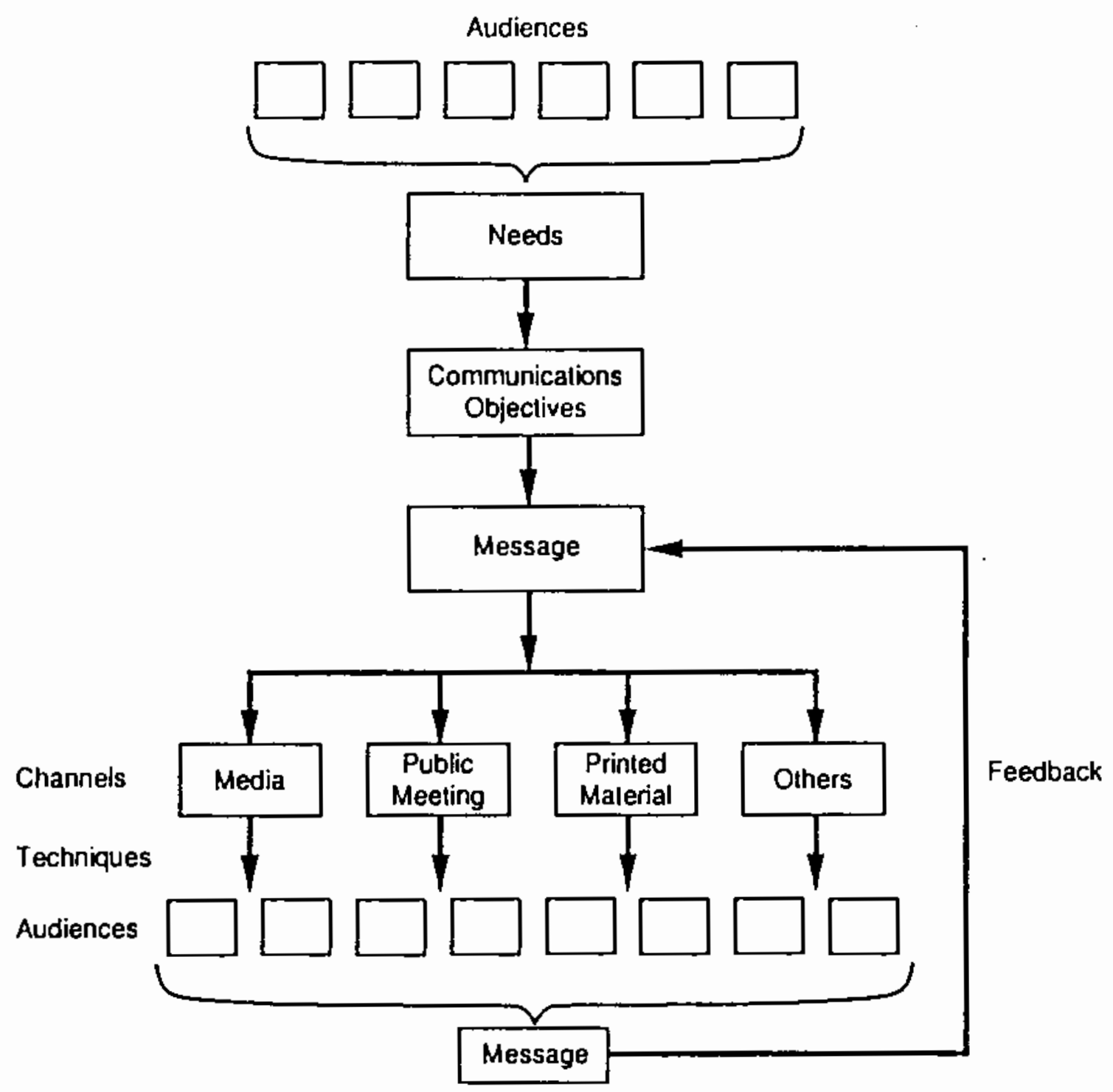

FIGURE 3.1. The Communications Process

required to make sure the process is continuing to meet the needs of the audience and satisfy the communications objectives of the project.

\subsection{COMMUNICATION OBJECTIVES}

Communication can be initiated by government agencies, environmental activists, private industry, citizens, the medical community, or any other interested party. Regardless of the initiating entity, group or individual, risk communication is based on an intended outcome. The outcome depends upon the communication objective. 
In risk management, four risk communication objectives are identified. One is to inform and educate, as in increasing a knowledge base. Another is to modify behavior, as in convincing an audience to wear seat belts. The third is to resolve conflicts or problems, as in determining a site for hazardous waste disposal. The fourth is to issue disaster warnings, such as hurricane warnings (Covello et al. 1987).

The general communication objective of the HEDR Project is to educate and inform. Each person involved in the communication process must gain an adequate understanding in order to make appropriate choices, given his or her values (National Research Council 1989). Given dose estimates, people will need to make judgments regarding the risk of their estimated exposure. These judgments may address issues such as, "Was I at risk? How certain is the probability of harm? Is the risk acceptable? What should I do now?" But before the risk information will be useful and relevant, an element of education is likely to be required.

The public's perception of radiation risks is often very different from the experts' perceptions (Slovic 1989; Fischhoff et al. 1982). The public may perceive far greater risks regarding some radiation technologies than do experts. In other instances, the public may perceive risks as being far lower than experts do (Slovic 1989). Therefore, an education process may be necessary to help the public learn about radiation and the consequences of different radiation exposures.

An information and education goal may seem simplistic for a project of this magnitude. The information objective, however, stands as the foundation upon which to build other goals. For example, trust and credibility are often earned during information exchanges. These additional goals will determine how the TSP and PNL choose to gather and distribute information. In other words, the information objective will drive the operational objectives. Information gains are the basic and foremost reason for performing the project. 


\subsection{THE MESSAGE}

The message for the HEDR Project will include four types of information: 1) the research process, 2) the research mode1, 3) the results, and 4) future research. The message is challenging because of several factors:

- deficiencies in existing data and in scientific understanding, resulting in uncertainties in risk estimates

- limits in assessing radiation release sequences, radiation pathways, human and animal exposures, geographic impacts, and consequences for sensitive populations, such as pregnant women, children, or the elderiy

- the technical complexity of the assessment, which may be unintelligible to the layperson (Covello et al. 1987).

Radiation exposure estimates will be based on many factors, including age, lifestyle, diet, location, weather patterns, and so on. Messages will include estimated radiation doses and the factors affecting these estimates. This message is heavily laden with quantitative information. However, experience and research show a more relevant message will include qualitative information addressing health and environmental implications (Hance, Chess and Sandman 1988; Krimsky and Plough, 1988; Davies and Cove110 1986; Cove110, von Winterfeldt and Slovic 1987; Fischhoff et al. 1981; National Research Council 1982). In other words, a relevant message will give the facts while responding to the audience's concerns.

Risk messages often reflect the knowledge, perspectives, and language of risk experts (Fischhoff et al. 1982). A risk message relevant to an intended audience, however, will reflect the perspective, technical capacity, and 1 anguage of that audience. A risk message should

- be personally relevant to the audience

- be clear and in plain language

- respect the audience and its concerns

- seek strictly to inform, not influence or manipulate (National Research Council 1989). 
This advice also means that information gaps should be discussed. This might include talking about limitations and uncertainties of the research, the model, the historical and reconstructed data, and the implications of these factors on the dose estimates.

A complete message will explore five areas: 1) the nature of the risk, 2) the nature of the benefits, 3) any available alternatives, 4) uncertainty in knowledge about the risks and the benefits, and 5) management issues (National Research Council 1989). Figure 3.2 is a suggested checklist for the design of a complete risk information message (National Research Counci] 1989).

This list provides a starting point to address technical complexity, uncertainty, data limitations, and health and environmental implications from the dose estimates. It can be modified to be more applicable to the HEDR Project. The complete message is the foundation upon which to build a balanced and open communications program.

\subsection{THE SOURCE}

The primary communication source for the HEDR Project will be members of the TSP, with technical support provided by Battelle staff, with some communications involving CDC staff. The diverse membership of the TSP includes national technical expertise in health physics, radiation pathways, demographics, radiation source terms, nuclear engineering, and statistics. Other members on the TSP represent the states of Washington and Oregon, Native Americans, and the public. The wide range of technical and communications expertise will influence the ISP's effectiveness as a communications source. On one hand, diversity lends itself to a more objective, believable source. On the other hand, effectiveness of the TSP may be lessened by

- disagreements among scientific experts, resulting in public confusion about the validity of the research

- failures to disclose limitations of risk assessments and resulting uncertainties

- limited understanding of the research, results, and methods 
INFORMATION ABOUT THE NATURE OF RISKS

1. What are the hazards of concern?

2. What is the probability of exposure to each hazard?

3. What is the distribution of exposure?

4. What is the probability of each type of harm from a given exposure to each hazard?

5. What are the sensitivities of different populations to each hazard?

6. How do exposures interact with exposures to other hazards?

7. What are the qualities of the hazard?

8. What is the total population risk?

INFORMATION ABOUT THE NATURE OF BENEFITS

1. What are the benefits associated with the hazard?

2. What is the probability that the projected benefit will actually follow the activity in question?

3. What are the qualities of the benefits?

4. Who benefits and in what ways?

5. How many people benefit and how long do benefits last?

6. Which groups get a disproportionate share of the benefits?

7. What is the total benefit?

\section{INFORMATION ON ALTERNATIVES}

1. What are the alternatives to the hazard in question?

2. What is the effectiveness of each alternative?

3. What are the risks and benefits of alternative actions and of not acting?

4. What are the costs and benefits of each alternative and how are they distributed?

UNCERTAINTIES IN KNOWLEDGE ABOUT RISKS

1. What are the weaknesses of available data?

2. What are the assumptions on which estimates are based?

3. How sensitive are the estimates to changes in assumptions?

4. How sensitive is the decision to changes in the estimates?

5. What other risk and risk control assessments have been made and why are they different from those now being offered?

\section{INFORMATION ON MANAGEMENT}

1. Who is responsible for the decision?

2. What issues have legal importance?

3. What constrains the decision?

4. What resources are available?

FIGURE 3.2. Checklist for a Complete Message (National Research Council 1989) 
- limited understanding of the interests, concerns, values, fears, priorities, and preferences of individuals and groups

- use of bureaucratic, legal, or technical jargon

- lack of trust and credibility (Covello et a1. 1987).

All of these issues will affect public perception of the TSP's credibility, objectivity, and technical competence. Some issues cannot be directly controlled. For instance, the TSP cannot control expert disagreement or lack of trust and credibility. Other issues, however, can be addressed. For example, the TSP can control the amount of technical jargon it uses to communicate. The TSP can also take steps to understand research outside their fields of expertise as well as the characteristics of its audience. Although the diversity of the TSP presents special challenges, its potential effectiveness as an information source can be a powerful way to earn credibility.

\subsection{THE CHANNELS}

Comnunications channels have significant impact on message reception. As mentioned earlier, the communication objective of the HEDR Project is to educate and inform the public so individuals can judge the impact of radiation doses they may have received from Hanford. To optimize the distribution of information, a variety of avenues must be considered, including

- mass media (radio, TV, newspapers, magazines, direct mail)

- individuat interactions (one to one)

- groups (classroom, worksite, special interests)

- organizational (professional associations)

- community (empioyers, schools, malls, health fairs, libraries)

- some combination of the above (National Cancer Institute 1989).

Some of the problems that may arise in using channels include selective, biased media reporting that emphasizes drama, wrongdoing, disagreements and 
conflict; premature disclosures of scientific information; and oversimplifications, distortions, and inaccuracies in interpreting technical risk information (Covello et al. 1987).

Psychological, social, cultural, and political factors can interact to "amplify risk" (Kasperson et a]. 1988). Slovic (1989) draws a meaningful analogy: an event can be thought of as a stone dropped in a pool. The ripples spread outward, encompassing first the directly affected, then the responsible company or agency, and, sometimes, an entire industry. Some events make small ripples, others make enormous ones. In the HEDR situation, the event may be the release of dose estimates. The magnitude of the ripples may impact many stakeholders. Farmers surrounding the Hanford region are a good example. If the ripples are small, farmers may see no impact on their business. However, if the ripples are very large, farmers may be economically affected, because people may be frightened enough to avoid buying agriculturat products grown in the Hanford region. Predicting the magnitude of amplification and its impacts is difficult. Although the message can be amplified in every step of the communication process, the channels can more powerfutiy amplify or diminish a message. The goal is to most effectively use channels so the message remains accurate and credible but still reaches the target audience.

\subsection{THE AUDIENCE}

The audience (the receiver) for the HEDR Project is diverse and numerous. The interested audience might include state and federal government agencies, corporations, business groups, unions, the media, scientists, professional organizations, public interest groups, educators, activist groups, and the medical community. The variety of groups within the audience implies a variety of messages appropriate for each group. Indeed, empirical and experiential evaluations arrive at the same conclusion: there is no such thing as the public. Instead there are several publics, each with its own characteristics, needs and demands. For convenience, however, this report refers to these publics simpiy as the audience. 
The personal message one draws from risk information will depend upon the perceived relevance of that message (Slovic 1986). Other challenges of an audience are

- inaccurate perceptions of levels of risk

- 1ack of interest in risk problems

- strong beliefs and opinions that are resistant to change

- exaggerated expectations about the research and its results

- desire and demands for scientific certainty

- difficulties in understanding probabilistic information (Covel10 et al. 1987).

These challenges can be met with a variety of approaches. On a basic communication level, the message must be formulated for an individual framework. In general, government and industry tend to communicate on a societal or "macro" level, rather than on an individual or "micro" level. For example, Johnson (1986) states, "our regulatory institutions are designed to deal with scientific risk assessments that cast risk in terms of the probabilities of adverse health effects as a result of national population exposures. What ordinary citizens want and need to know is this: what is safe to do in my own life?"

Communication on a micro-level is more meaningful to the individual because it can answer the direct concerns of the individual. Thus effective risk communication must occur on a micro-level, in a framework relevant to the individual.

Other approaches include consideration of information thresholds, preferences, and political agendas of the individual (Kasperson 1986). The information threshold refers to the technical capacity of the individuat. Some people understand highly technical information whereas others may understand only the most simplified results. Individual preferences should be also considered. Some people prefer uncomplicated, bottom-line answers; others prefer more detail. The TSP response to individual political agendas will affect the audience reception. Many people do not and will not care about radiation exposure. Others may feel a need to become politically 
active or to increase their political activity. The information needs of these groups are quite different. Communication strategies should be formuTated that respond to these differences. A11 in a11, consideration of audience characteristics such as perceptions, concerns, information thresholds, preferences, and political agendas can help to formulate communications that respond to the audience on their terms, resulting in a more relevant, understandable message. 


\subsection{KEY PRINCIPLES IN RISK COMMUNICATION}

The reviewed risk communication literature originated from many diverse viewpoints, ranging from academic postulates to anecdotal "lessons learned." Throughout the literature, however, some common principles appear. This report summarizes the most common and readily applicable of these principles.

The risk communication principles are short and simple. Explanation and evidence support each principle, adding justification and perhaps perspective, as to why the principle was chosen. The list is not exhaustive. However, it contains some of the main points necessary to build a foundation for a successful risk communication program.

\subsection{KNOW AND UNDERSTAND YOUR MESSAGE}

To develop trust and credibility, a clear, consistent, and accurate message must be conveyed (Covello and Allen 1988; Davies and Covello 1986; Kasperson et al. 1988). Communication is most effective when the representatives of a team are clearly identified, accustomed to working together, and have a sense of team leadership and composition (Thayer 1989). When team members appear to send contradictory or inconsistent messages, hard-earned credibility erodes. Although it may seem obvious, the communications team must know and understand the message. For the HEDR Project, the communications team will include the TSP, PNL and the CDC. It is easy for the public to be confused or to develop misunderstandings about the message, especially with a communication source as diverse as the TSP, PNL, and the CDC.

One approach to ensuring a consistent message and to developing a stronger team is to train the speakers. Speaker's training can enhance understanding of the technical research, methods and results. It can provide tools for effective interactions with the public and the media (Chess 1987). Training techniques might include role playing and practice question-andanswer sessions; tools might include a speaker's packet and audio-visual aids. 
Another approach is to practice. Practice presentations offer the opportunity to evaluate the presentation for content, flow, and polish. In these sessions, speakers can also practice handling difficult questions (Sachsman 1985). Although speakers may certainly approach a presentation with their own points of view, every speaker is responsible for conveying technically accurate and consistent information. The practice presentation allows for mistakes in a safe environment.

A third approach to maximizing accuracy and consistency is to develop a peer review process. This is especially appropriate if speakers provide their own materials, i.e., "canned" presentations are not used. A peer review process will check if accurate materials are used and if the desired message is presented. As noted earlier, consistently getting out the right information is key in establishing trust and credibjlity (Hance et a1. 1988).

These approaches may help speakers talk about project limitations and uncertainties; understand the research, methods, and results; understand and respond to qualitative concerns of different audiences; and relate personally to the audience (Covello et al. 1987). The content and quality of the spoken message will be improved. And, a consistent message given by various speakers is a more powerful message. The message will help establish the TSP, the CDC, and PNL staff as credible and trustworthy sources. But knowing and understanding the message is only the first step in any communication program.

\subsection{KNOW YOUR OBJECTIVE}

Risk communication is difficult. The risk communicator must decide many things. Who should know? How much should they know? Will they want to know? How much, at a minimum, needs to be understood? Can action be taken? What is the role of the interested audience, if any? Before these questions are answered, the goals of the risk communication must be considered.

All too often, risk communication efforts have been pursued with implicit or impractical goals. Risk communication activities must be matters of conscious design, not an afterthought to the research. A general design might be to 1) determine the communication objective; 2) evaluate the risk 
information (determine its strengths and weaknesses); and 3) aim communication at the various subgroups (Covello and Allen 1988). Such a process can set the general context of the risk communication effort.

Explicit consideration of objectives can improve risk communication. Risk communicators must know and be clear about the nature of their problem and about the objectives of the communication. For example, it is essential that communicators be clear about whether their role is that of a facilitator or a promoter (Davies et al. 1986). A speaker and an audience will respond differently in an interactive, facilitated exchange than in a passive, lectured medium. Articulating the objective clarifies the intent of the communication (Covello et al. 1987).

Clarifying the objective can clarify expectations held by the comnunicator and the audience. In fact, one source of conflict arises from differences in expectations (Kasperson 1986). Tension can arise between the TSP and the public if the public's role in the process is not clarified. If expectations are not clarified, the audience may feel misled. The sooner expectations and roles are known and shared, the earlier potential conflicts can be resolved. If public participation is to be limited, then it should be made clear, along with an explanation. The ideal solution is to find out what type of invoivement communities would prefer and respond accordingly (Hance et al. 1988). Because knowing and communicating the objectives may be key in reducing conflict and establishing credibility, such activity is paramount.

\subsection{KNOW YOUR AUDIENCE AND ESTABLISH DIALOGUE EARLY}

Research and experience stress the importance of knowing the audience (Slovic 1986, 1987, 1989; Fischhoff et a1. 1982, 1983; Hance et a1. 1988; Cove110 et al. 1987). For the HEDR Project, knowing the audience is to identify who is interested in Hanford radiation risks, and why. The TSP, $\mathrm{PNL}$, and the CDC must understand the concerns, opinions, information needs, and emotions of the audience, then respond, not only to quantitative information needs, but to qualitative information needs as well. An effective 
message will speak to the audience on its terms (Slovic 1986). What are these terms? The TSP must understand

- what the audience knows, beljeves, and does not believe about the Hanford radiation risks and ways to control them

- what quantitative and qualitative information the audience needs to make critical decisions

- how the audience thinks about risk (Nationa] Research Counci] 1989).

If the TSP can interact with the audience on its own terms, an effective dialogue will be opened. The fact that dialogue is a two-way exchange of listening and sharing information with the interested parties cannot be overemphasized. Good communication is not teaching people to worry about the "right" risks, nor is it converting them to the "correct" point of view (Shaw and Herb 1988). Good communication is an exchange that considers facts and emotions.

Dialogue should begin early. One reason for involving the public early is to find out what people want to know and what the research will determine. For example, many people may want to know the health effects of the estimated radiation doses. The HEDR Project, however, will only provide estimated doses and will not identify health effects. Clarifying and resolving such differences in expectations early can prevent unnecessary confrontational exchanges later in the project.

Another reason for establishing early dialogue is to begin an education process that will give the public a baseline for understanding the research results. The sooner the audience can understand the research results, the sooner the communication effort can focus on the information side rather than the education side. In addition, the sooner people become familiar with aspects of the project (e.g., the researchers, the TSP, the data, and the problems), the more time they have to develop perceptions of the project. Additionally, the more time the TSP and PNL have to develop credibility. Knowing the audience, establishing dialogue, and early involvement are fundamenta] in risk communication. 


\subsection{BE AWARE OF OUTRAGE FACTORS}

The public's perception of risk is often very different from the expert's perception, especially in nuclear radiation issues (Slovic 1989; Fischhoff et al. 1982, 1983). While experts might say the actual risk from the nuclear industry is negligible, the public will often have an opposite perception. In fact, the public judges the benefits from nuclear power to be quite small and the risks to be unacceptably great (Slovic 1987). Why this dramatic discrepancy? The difference is outrage.

Outrage factors are variables that influence public perception. When ignored, outrage factors raise the level of hostility between those who send a message and those who receive it (the TSP and the public, respectively). To the public, the perceived risk associated with the nuclear industry is not voluntary (it is imposed by government or industry). In addition, it is uncontrollable (to the individual); undetectable (cannot be seen, smelled, heard or touched); unknown; highly dreaded; unequitable (those who benefit may not bear a proportionate amount of risk and vice versa); potentially catastrophic; and fatal, with unknown consequences for future generations (Slovic 1989). As Hance et al. (1988) suggest, "The greater the number and seriousness of these factors, the greater the likelihood of public concern, regardless of the data." To a large segment of the population, these factors are quite applicable to issues surrounding the HEDR Project.

The credibility of the information source is crucial in dealing with outrage. Establishing credibility in the eyes of the public is one of the most challenging aspects of the HEDR Project. The project is funded by the DOE and the work is performed by a DOE contractor, PNL. This fact leads some of the audience to feel that PNL may produce results biased in favor of the DOE. The widespread understanding that DOE has operated under strict security and, in the eyes of many, secrecy in the past has created anger and skepticism among some in the audience. Some are afraid DOE will not release all information pertinent to the project or believe DOE is continuing to secretively damage the environment with radioactive or hazardous waste. 
Radiation releases are an issue: many people are frightened, enraged and worried about the potential effects from Hanford radiation and radioactive waste. The fact that many people suspect the releases were intentional intensifies these feelings. Some people may see the HEDR Project as another DOE attempt to placate the public. Clearly, the stage is set for community outrage (and in some Hanford situations unrelated to HEDR, the outraged community is apparent). Unfortunately, there is no magic formula for reducing outrage. However, there are some strategies that may heip communicators deal with outrage.

The main point is to pay as much attention to outrage factors and to the community's concerns as to the scientific research (Hance et a1. 1988); that is, respond to qualitative factors as well as to quantitative facts (Covello et a1. 1987; National Research Council 1982). The TSP should 1isten to the public's concerns with respect and understanding. Responding to concerns on a personal, perhaps emotional, level can help. A simple statement such as, "I, too, would be angry in your situation," or "Yes, the potential effects from Hanford radiation concern me, too," can help the audience feel as if it has been heard. Outrage will not disappear; the strategies mentioned above may, however, help people direct their outrage at the issues rather than the process.

\subsection{PAY ATTENTION TO THE PROCESS}

The National Research Council (1989) states, "Solving the problems of risk communication is as much about improving procedures as improving content." The Council adds that better risk communication is not a matter of crafting better messages. Procedural solutions are necessary to enhance credibility, to ensure accuracy, to understand the audience and its concerns, and to gain insight into how messages are actually understood. Risk communication must be an early, deliberate, and ongoing process.

Four management objectives are identified for an improved risk communication process: 1) set realistic goals; 2) safeguard openness; 3) provide a balanced perspective; and 4) foster competence (National Research Council 1989). 
Realistic goal setting is discussed in a prior section. It emphasizes explicit consideration of practical, achievable risk communication activities. Clarification of motives, objectives and expectations of the source organization is necessary. Effective communication of these expectations will likely prevent or reduce conflict with the intended audience, resulting in a more believable and effective process.

Openness is the honest and ongoing exchange of information between interested parties. In a democracy, openness is highly valued. The TSP and PNL are publicly accountable for the quality of the HEDR research and the results produced by the study. The TSP has adopted openness as a matter of principle and as an operating procedure. However, the desire to be open often brings about difficult questions of information release.

Information release can be a delicate issue. If data are released too early and contain errors, credibility may be destroyed. However, if data are released too late, the public may feel as if something is being hidden, which also destroys credibility.

The TSP and PNL have carefully considered the timing of information release. On one hand, there is the desire to share information as it becomes available. On the other hand, there is a need to be cautious about sharing radiation doses without adding interpretation and meaning.

The Phase I goal of the project is to develop a model to estimate doses and test the model's assumptions and Timitations. The estimates are preliminary; additional research will produce final estimates in 1993 . The preliminary results may be very different from the final results. As such, there are concerns about sharing information that will change.

With careful planning, however, the desire for openness and the need to add interpretation and meaning need not be mutually exclusive. It may help to first understand the reasons for early information release:

- The information may leak anyway. When it does, trust and credibility are apt to be lost.

- The accuracy of information is best controlled by those who first present it. 
- People are entitled to information that affects their lives.

- Less work is required to release information early than to respond to inquiries, attacks, etc., that might result from delayed release.

- The public is more likely to trust information that is released promptly.

- People may feel angry and resentful about not learning of information earlier.

- People are more likely to overestimate the risk if the information is withheld (Hance et al. 1988).

1.2 Generally, agencies tend to err on the side of delaying release too long, rarely on the side of releasing too quickly. Given these reasons, clearly it is important to consider early information release. However, early release will not replace careful planning and management of the information process. Strategies can and should be developed that invite early release of meaningful information. Partial information can also be shared as it becomes available, and public involvement in the decision making process regarding the study can also serve as a mechanism for early information release. A carefully $\mathrm{planned}$ process for information release can meet information needs without hastily "dumping" information.

Balance and accuracy in messages can prevent real and perceived distortions (National Research Council 1989). The Council adds that distortion can enter at two stages: in the materials that are supplied for the message and the composition of the message. Three types of biases are cited: 1) the researcher's personal value judgments about what the risk outcome should be; 2) the researcher's belief about where the organization's self-interest lies; and 3) "expert bias," which can lead experts to exaggerate the uncertainty or the precision of their estimates. To elicit the best, objective technical information, independent peer review and outside pre-testing of alternative messages should be considered.

Competence can be fostered through balanced procedures. The risk message should be developed as part of an overall, deliberate risk communication strategy that does not sacrifice scientific quality (National Research Council 1989). A process of knowing one's audience and responding appropriately 
is critical. Feedback and evaluation will further enhance the process, so that we learn from the successes and deficiencies of the risk communication efforts.

Attention to objectives such as realistic goals, openness, balance and competence is an important part of earning credibility. Fischhoff (Hance et al. 1988) said, "People read the agencies and their actions more carefully than they read the details of the studies..." While procedures cannot ensure successful risk communication, poor procedures can almost guarantee failure. Therefore, attention to process is as important as the research.

\subsection{DEAL DIRECTLY WITH UNCERTAINTY}

Uncertainty may be one of the most difficult aspects of risk communication. The researcher may wish to explain the entire gamut of uncertainty in the science. The public may demand a definite, bottom-line answer: Is it safe? The risk communicator may avoid any discussion of uncertainty, fearing a smear on the credibility of the research. While all of these are understandable reactions, none are appropriate.

A well-informed choice about the radiation risks presented by the Hanford Site requires a wide range of knowledge. For example, it requires knowledge on radiation pathways, radiation sources, health effects from different radiation sources, factors affecting exposure (1ifestyle, age, diet, etc.), social values, economic costs, statistics, and so on. In practice, it is impossible to gather all this knowledge. Therefore, the scientific risk estimate is based on incomplete knowledge combined with assumptions. Each is a source of uncertainty that should be ascribed to the estimate (National Research Council 1989).

Scientists are taught to represent uncertainty accurately. To do so, they must make judgments regarding the meaning of available information and the degree of reliability. This may result in 1) inappropriate reliance on limited data; 2) a tendency to impose order on random events; 3) a tendency 
to fit ambiguous data into predispositions; 4) a tendency to systematically omit components of risk (i.e., human error); and 5) an overconfidence in the reliability of the analysis.

These tendencies can bias scientific judgment in the direction of overconfidence in the estimate (National Research Council 1989). As a result, there may be some skepticism about definitive claims by scientists. There are several suggestions for explaining uncertainty.

One suggestion is to provide the public with background about the nature of science (Ruckelshaus 1983). Science explores the unknown. Its purpose is to discover and characterize the unknown. Usually, it is a slow process. The scientist begins with an idea or concept and slowly tests it. Uncertainty is chipped away until the idea is proved or disproved. Science is usually not a "yes" or "no" enterprise. The scientific process should be explained to the public by scientists.

The TSP should consider giving the public background information about the particular limitations of the HEDR study. An appropriate discussion might include an explanation to clarify the facts and the assumptions in the research. Then, the TSP and PNL can explain the methods it proposes to use to continue the research. An explanation of why some methods are more important than others is also recommended.

Another suggestion is to involve the public and allow for as much individual control as possible. One idea developed for the HEDR Project is to provide a computer model that can calculate an estimated dose to the individual, based on the individual's recollection of certain factors. These factors include lifestyle (urban or rural), diet, age, location, and so on. Although the public may not be directly involved in the research, use of the computer model gives the research results individual relevance and meaning.

The word "caution" should be used. The research community often uses the word "conservative" to describe an estimate. However, some of the public may misinterpret this to mean a low estimate. Therefore, for clarification, communicators should stress the caution in the research. 
Finally, any disagreement about the research or the process should be acknowledged in the beginning. Several aspects of the HEDR study hold the potential for differences of opinion. For instance, much of the HEDR data are $01 d$ and some have been reconstructed from memories of study area residents. Many new research methods have been developed specifically for this project. Criticism can arise from experts, activists, the public, the government, or anyone e]se. The TSP and PNL should identify and acknowledge any uncertainties in the process or the results.

Discussing the nature of science, the limitations and assumptions of the HEDR Project, how the answers are being found, resolving uncertainty for individuals, stressing the caution of the research, and acknowledging disagreements are recommended ways to approach uncertainty with the public. In addition, discussions should focus on the implications of uncertainty on the results, not necessarily on the science. Such strategies will help establish the credibility of the project.

\subsection{EXPLAINING RISK}

Risk comparisons are one of the most common ways to explain risk. However, risk comparisons can also be one of the most difficult ways to communicate.

When lay and expert values differ, reducing different kinds of hazard to a common metric (such as number of fatalities a year), and presenting comparisons only on that metric have great potential to produce misunderstanding and conflict and to engender mistrust of expertise (National Research Council 1989).

In many cases, risk comparisons are so qualitatively different that they evoke outrage and hostility among the public (Bean 1988; Covello et al. 1987; National Research Council 1989; Slovic 1986; Sandman 1987). It may seem to the public as if the intent of the comparison is to minimize the risk (by equating it to a seemingly trivial risk). It may appear as if the comparisons are used to influence or mislead the public. Many communicators hope a risk comparison will visually explain a risk relative to a "worry threshold." But for informed decisions other critical data, such as motivation, history, future decisions, social acceptability, and so on, are important as well 
(National Research Council 1989). Risk comparisons, used with caution, can be helpful in adding insight to an overall discussion of the risk.

The magnitude of particular risks can be conveyed when events that occur in the same decision context (j.e., flying and driving to the same destination) and that have a similar outcome can be compared. Multiple risk comparisons can also help. For the HEDR Project, comparisons can be part of the risk message in explaining 1) very small probabilities and 2) the relative importance of different causes of the same hazard, e.g., radon radiation versus Hanford radiation exposures (National Research Council 1989).

Communicators must be sensitive to the situations in which they use risk comparisons (Covello et al. 1987). Risk comparisons can be used when the source of the comparison is highly credible and neutral; when the situation is not heavily laden with emotion; when the comparison in itself does not dispose of the risk; and when the comparison is aimed at clarifying the issue, not at minimizing or dismissing it (Sandman 1987). In summary, risk comparisons can be helpful, but they must be used carefully.

There are other ways to explain technical information without using risk comparisons. Because the particulars of nuclear production and radiation are unknown and highly feared by much of the population, some of these other methods may be beneficial in approaching the education goal of the HEDR Project. As mentioned earlier, a variety of communication avenues must be pursued to reach such a diverse audience. Some of these other methods include the causal model, the fault tree, materials and energy flow diagrams, and a risk analysis checklist as developed by Fischhoff (National Research Council 1989). An example of each method is in Appendix C.

The causal model may be very relevant for the HEDR project. According to Fischhoff, the causal model

. . is a way to organize the full set of factors leading to and from an environmental mishap, both when getting the story and when telling it. The example [see Appendix C, Figure C.1] is an automobile accident, traced from the need for transportation to the secondary consequence of the collision. Between each stage, there is some opportunity for an intervention to reduce the risk of an accident. By organizing information about the hazard in a chronological sequence, this scheme helps ensure that nothing is left 
out . . . Applied to an "irregular event" at a nuclear power station, for example, this protocol would work to remind a reporter of such (left-handed) causes as the need for energy and... such (right-handed) consequences as the costs of retooling other plants designed like the affected plant or the need to burn more fossil fuels if the plant is taken off line (without compensating reductions' in energy consumption).

In the HEDR situation, the causal model may provide a visual representation of a very complicated sequence. From the original need for plutonium to the secondary consequence of radioactive releases, the schematic could represent an overall, chronological picture. The causal model could remind the audience of the need for plutonium (as perceived in the 1940s) as well as the consequences of production, e.g., atomic weapons or the release of radioactive material. Specifically pointing out the negative events may make the results appear more objective. The causal model, then, provides a pictorial sequence of events describing the overall picture of the hazard and its consequences.

A variant of the causal model, the fault tree (see Appendix C, Figure C.2) lays out the sequence of events that must occur for a particular accident to happen. Actual fault trees may be intricately involved, but are used to organize and coordinate thinking. They may be used to estimate overall riskiness of nuclear facilities. In effect, fault trees detail the right-handed parts of a causal model. They can help a reporter order the pieces of a story collected from different sources. Like the causal model, the fault tree could clarify the possible hazards and consequences of plutonium production for those who are not familiar with production plants and radiation pathways.

Materials and energy flow diagrams (see Appendix C, Figure C.3) are commonly used in engineering models. If something is neither created nor destroyed in a process, then one should be able to account schematically for every part. In environmental affairs, one wants to account for all toxic materials. Likewise, the HEDR project can schematically account for the radiation produced in a plutonium production process. It is important to know and understand where each toxic agent comes from and where each goes. 
Finally, Fischhoff suggests a list of questions that can be asked in a risk analysis in order to clarify what problem has been addressed and how well it has been solved. The list in the example (see Appendix C, Figure C.4) was compiled for a citizen group concerned with pesticides. Its members had mastered many details, such as toxicology and biochemistry, when they were confronted with a risk analysis. In principle, risk analysis does no more than organize information in a way that allows overall estimates of risk to be computed. It can facilitate citizen access by forcing all the facts out on the table. Such a checklist of questions can clarify the analyses performed. These methods to explain risk are by no means comprehensive. These few techniques may help explain the process and quantitative aspects of the results. They are examples of alternatives to risk comparisons. But used alone, these methods will not answer the emotional concerns of an audience. Therefore, these methods are suggested enhancements to a larger communication strategy and process.

\subsection{FEEDBACK AND EVALUATION}

A successful risk communication program will learn from its successes and its deficiencies. To do so, a feedback and evaluation process is necessary for the entire duration of the project. The feedback process can be simple, yet provide invaluable information. Feedback and evaluation can begin with documentation of current communication efforts to provide a foundation from which to build. In addition, speakers can be debriefed to develop feedback and recommendations for the future. Suggestions from external agencies involved in the dialogue can be solicited and more recommendations developed (Chess 1987). Yet another evaluation approach is with focus groups.

Focus groups are informal discussions with a small group of people to probe their attitudes, opinions, and concerns about a specific topic. Focus groups can be an important technique in understanding how people respond to risk. Specific roles of focus groups in risk communication might include 
- exploring risk perceptions

- evaluating perceptual cues and information processing

- pretesting risk communication materials

- selecting risk communication channels

- assessing risk communication effectiveness (Desvousges and Smith 1988).

Focus groups can offer insights to make risk communication more effective by helping communicators listen to consumers of risk messages. They provide opportunities to listen to the everyday language people use to describe risks. The information gathered from these approaches is qualitative. It is not statistically valid. It will however, add valuable perspective to risk communication efforts in developing a communications program. All of these approaches are effective ways to gain feedback and evaluation as well. Feedback and evaluation can lead to recommendations for even better risk communication efforts.

These key principles are a compilation of experience, common sense, and research. There is no magic formula for making risk communication easier. In fact, these key principles cannot guarantee a successfui risk communication program. Instead, their use may prevent the TSP and PNL from inadvertently alienating their audience. Use of these principles may help improve dialogue with the audience, help communicators understand public responses to risks posed by the Hanford radiation releases, and initiate more effective interaction with the community. More importantly, they can help establish the credibility and objectivity of the HEDR Project research.

The work described in this report was conducted in accordance with the requirements as interpreted by PNL's Quality Assurance (QA) program. Drafts of this document underwent internal independent technical review. 
. 


\section{REFERENCES}

Bean, M. C. February 1988. "Speaking of Risk." Civil Engineering, pp. $59-61$.

Bick, T., C. Hohenemser and R. W. Kates. 1979. "Target: Highway Risks." Environment. 21(2):7-15, 29-38.

Chess, C. 1987. "Encouraging Effective Risk Communication in Government: Suggestions for Agency Management." Environmental Communication Research Program, New Brunswick, New Jersey.

Covel 1o, V. T. and F. W. Allen. 1988. "Seven Cardinal Rules of Risk Communication." U.S. Environmental Protection Agency, Office of Policy Analysis, Washington, D.C.

Covello, V. T., D. von Winterfeldt and P. Slovic. 1987. "Communicating Scientific Information about Health and Environmental Risks: Problems and Opportunities from a Social and Behavioral Perspective." Uncertainty in Risk Assessment, Risk Management, and Decision Making. ed. Covello, V. T., L. Lave, A. Moghissi, and V. Uppuluri, pp. 221-239, Plenum Press, New York, New York.

Davies, C. J. and V. T. Covel10. 1986. "Risk Comnunication." Proceedings of the National Conference on Risk Communication. Conservation Foundation. Washington, D.C.

Desvousges, W. H. and V. K. Smith. 1988. "Focus Groups and Risk Communication: The "Science" of Listening to Data." Risk Analysis 8(4):479-484.

Fischhoff, B., P. Slovic and S. Lichtenstein. 1982. "Lay Foibles and Expert Fables in Judgments about Risk." The American Statistician 36(3)2:240-255.

Fischhoff, B., S. Lichtenstein, P. Slovic, S. L. Derby and R. L. Keeney. 1981. Acceptable Risk. Press Syndicate of the University of Cambridge. New York, New York.

Fischhoff, B., P. Slovic and S. Lichtenstein. 1983. "The Public' vs. 'the Experts': Perceived vs. Actual Disagreements about Risks of Nuclear Power." The Analysis of Actual Versus Perceived Risks. ed. Covello, V. T., Flamm, W., Rodricks, J., and Tardiff, R., Plenum Press, New York, New York.

Hance, B., C. Chess and P. M. Sandman. 1988. Improving Djalogue With Communities: A Risk Communication Manual for Government. New Jersey Agricultural Experiment Station, Cook College, Rutgers University, New Brunswick, New Jersey. 
Johnson, R. 1986. "EDB (Ethylene Dibromide)." Summary of Panel Discussion. Proceedings of the National Conference on Risk Communication. ed. Davies, C. J. and V. T. Covello, pp. 83-85. Conservation Foundation. Washington, D.C.

Kasperson, R. E. 1986. "Six Propositions on Public Participation and Their Relevance for Risk Communication." Risk Analysis 6(3):275-281.

Kasperson, R. E., 0. Renn, P. Solvic, H. S. Brown, J. Emel, R. Goble, J. X. Kasperson, and S. Ratick. 1988. "The Social Amplification of Risk: A Conceptual Framework." Risk Analysis 8(2):177-197.

Krimsky, S. and A. Plough. 1988. Environmental Hazards: Communicating Risks as a Social Process. Auburn House Publishing Company, Daver, Massachusetts.

National Cancer Institute. 1989. "Making Health Commuications Programs Work: A PTanner's Guide." NIH \#89-1493. Office of Cancer Communications, Bethesda, Maryland.

National Research Council. 1989. Improving Risk Communication. National Academy Press, Washington, D.C.

National Research Council. 1982. Risk and Decision Making: Perspectives and Research. National Academy Press, Washington, D.C.

Ruckelshaus, W. D. 1983. "Science, Risk, and Public Policy." Science 221():1026-1028.

Sachsman, D. B. 1985. "Linking the Scientist and the Journal ist." HAZPRO '85 Professional Certification Symposium and Exposition, Baltimore, Maryland.

Sandman, P. M. 1987. "Explaining Risk to Non-Experts." Emergency Preparedness Digest, pp.25-29.

Shaw, J. A., and J. Herb. October 1988. "Risk Communication: An Avenue for Public Involvement." Journal AWWA, pp. 42-44.

Slovic, P. 1989. "Perception of Risk from Radiation." Proceedings of the 25th Annual Meeting of the National Council on Radiation Protection and Measurements. (1n press)

Slovic, P. 1987. "Perception of Risk." Science 236(4699):280-285.

Slovic, P. 1986. "Informing and Educating the Public About Risk." Risk Analysis 6(4):403-415.

Thayer, A. M. 1989. "Alar Controversy Mirrors Differences in Risk Perceptions." Chemical and Engineering News. 67(35):7-14. 


\section{BIBLIOGRAPHY}

Ahearne, J. F. 1987. "Nuclear Power After Chernoby1." Science $236(4802): 673-679$.

American Chemical Society Working Group on Risk Communication. 1988.' "Chemical Risk Communication: Preparing for Community lnterest in Chemical Release Data." American Chemical Society, Washington, D.C.

Baybutt, P. 1989. "Communicating Risk, Step by Step." Hydrocarbon Processing (6):85-90.

Bean, M. C. February 1988. "Speaking of Risk." Civil Engineering, pp. $59-61$.

Bick, T., C. Hohenemser and R. W. Kates. 1979. "Target: Highway Risks." Environment. 21(2):7-15, 29-38.

Britain, V. A. September 1974. "Radiation: Benefit vs. Risk." FDA Consumer.

Chess, C. 1987. "Encouraging Effective Risk Communication in Government: Suggestions for Agency Management." Environmental Communication Research Program, New Brunswick, New Jersey.

Chess, C, and B. J. Hance. 1989. "Making Risk Communication Agency Reality." Environment 31(5):11-39.

Cohen, B. L. and I. Lee. 1978. "A Catalog of Risks." Health Physics $36(6): 707-722$.

Covel10, V. T. and F. W. Allen. 1988. "Seven Cardinal Rules of Risk Communication." U.S. Environmental Protection Agency, Office of Policy Analysis, Washington, D.C.

Covello, V. T., P. M. Sandman and P. Slovic. 1988. Risk Communication, Risk Statistics, and Risk Comparisons: A Manual for Plant Managers. Chemical Manufacturers Association, Washington, D.C.

Covello, V. T., D. von Winterfeldt, and P. Slovic. 1987. "Communicating Scientific lnformation about Health and Environmental Risks: Problems and Opportunities from a Social and Behavioral Perspective." Uncertainty in Risk Assessment, Risk Management, and Decision Making. ed. Covello, V. T., L. Lave, A. Moghissi, and V. Uppuluri, pp. 221-239, Plenum Press, New York, New York.

Davies, C. J. and V. T. Covello. 1986. "Risk Communication." Proceedings of the National Conference on Risk Communication. Conservation Foundation. Washington, D.C. 
Desvousges, W. H., and V. K. Smith. 1988. "Focus Groups and Risk Communication: The "Science" of Listening to Data." Risk Analysis 8(4):479-484.

Dietz, T., P. Stern and R. Rycroft. 1989. "Definitions of Conflict and the Legitimation of Resources: The Case of Environmenta] Risk." Sociological Forum 4(1):47-70.

Environmental Protection Agency (U.S.). 1987. Risk Assessment, Management, Communication: A Guide to Selected Sources. Update. National Technica] Information Services, Washington, D.C.

Fischhoff, B., P. Slovic and S. Lichtenstein. 1982. "Lay Foibles and Expert Fables in Judgments about Risk." The American Statistician 36(3)2:240-255.

Fischhoff, B., S. Lichtenstein, P. Slovic, S. L. Derby and R. L. Keeney. 1981. Acceptable Risk. Press Syndicate of the University of Cambridge. New York, New York.

Fischhoff, B., P. Slovic and S. Lichtenstein. 1983. "The Public' vs. 'the Experts': Perceived vs. Actual Disagreements about Risks of Nuclear Power." The Analysis of Actual Versus Perceived Risks. ed. Covello, V. T., Flamm, H., Rodricks, J., and Tardiff, R., Plenum Press, New York, New York.

Forscher, F. 1986. "Understanding Risks." Hazard Prevention (July/August):26-28.

Friedman, R. S. 1989. "Dealing With Public Perceptions of Health Risks in a Nuclear World." Nuclear Plant Journal 7(2):66-75.

Gundry, K. G., and T. A. Heberlein. 1984. "Do Public Meetings Represent the Public?" APA Journal, Spring, pp. 175-182.

Hance, B., C. Chess and P. M. Sandman. 1988. Improving Dialogue With Communities: A Risk Communication Manual for Government. New Jersey Agricultura1 Experiment Station, Cook Col1ege, Rutgers University, New Brunswick, New Jersey.

Heberlein, T. A. 1976. Principles of Public Involvement. Department of Rural Sociology, University of Wisconsin-Madison, Madison, Wisconsin.

Hohenemser, C., R. Goble, J. X. Kasperson, R. E. Kasperson, R. W. Kates, P. Collins, A. Goldman, P. Slovic, B. Fischhoff, S. Lichtenstein, and M. Layman. 1986. "Methods for Analyzing and Comparing Technological Haz" ards." Risk Evaluation and Management, ed. Covello, V. T., J. Menkes, and J. Mumpower, pp. 249-274. Plenum Press, New York, New York.

Johnson, B. L. 1987. "Health Risk Communication at the Agency for Toxic Substances and Disease Registry." Guest Editorial. Risk Analysis $7(4): 409-412$. 
Johnson, R. 1986. "EDB (Ethylene Dibromide)." Summary of Panel Discussion. Proceedings of the National Conference on Risk Communication. ed. Davies, C. J. and V. T. Covello, pp. 83-85. Conservation Foundation. Washington, D.C.

Kamrin, M. A. 1987. "Communicating Risk Assessment to the Public." Letter to the Editor. Environmental Toxicology and Chemistry 6:85-87.

Kasperson, R. E. 1986. "Six Propositions on Public Participation and Their Relevance for Risk Communication." Risk Analysis 6(3):275-281.

Kasperson, R. E., 0. Renn, P. Slovic, H. S. Brown, J. Emel, R. Goble, J. X. Kasperson, and S. Ratick. 1988. "The Social Amplification of Risk: A Conceptual Framework." Risk Analysis 8(2):177-197.

Keeney, R. L. and D. von Winterfeldt. 1986. "Improving Risk Communication." Risk Analysis 6(4):417-424.

Konheim, C. S. 1988. "Risk Communication in the Real World." Risk Analysis $8(3): 367-373$.

Kraft, Michael E. 1989. Risk Perception and the Politics of Citizen Participation: The Case of Radioactive Waste Management. Presented at the Risk Analysis Conference, October 30, 31, and November 1, 1989, San Francisco, California.

Krimsky, S, and A. Plough. 1988. Environmental Hazards: Communicating Risks as a Social Process. Auburn House Publishing Company, Daver, Massachusetts.

Litai, D., D. D. Lanning, and N. C. Rasmussen. 1983. "The Public Perception of Risk." The Analysis of Actual Versus Perceived Risks. ed. Covello, V. T., W. G. Flamm, J. Rodricks, and R. Tardiff, Plenum Press, New York, New York.

Michaud, G. R. 1989. "Accepting New Technology: Community Relations for Mobile Incineration in Illinois." Presented at the Risk Analysis Conference, October 30, 31, and November 1, 1989, San Francisco, California.

Mumpower, J. L. 1988. "Lottery Games and Risky Technologies: Communications About Low-Probability/High-Consequence Events." Risk Analysis $8(2): 231-235$.

National Cancer Institute. 1989. "Making Health Communications Programs Work: A Planner's Guide." NIH \#89-1493. Office of Cancer Communications, Bethesda, Maryland.

National Research Council. 1989. Improving Risk Communication. National Acadeny Press, Washington, D.C. 
National Research Counci1. 1982. Risk and Decision Making: Perspectives and Research. National Academy Press, Washington, D.C.

Nealey, S. M., and E. B. Liebow. 1988. Assessing Social and Economic Effects of Perceived Risk: Workshop Summary. PNL-6515, Pacific Northwest Laboratory, Richland, Washington.

Otway, H. and B. Wynne 1989. "Risk Communication: Paradigm and Paradox." Risk Analysis $9(2): 141-145$.

0tway, H. 1987. "Experts, Risk Communication, and Democracy." Risk Analysis 7(2):125-129.

Philipson, L. L. 1986. "Risk Evaluation: A Review of the Literature." Risk Evaluation and Management, ed. Covel 10, V. T., J. Menkes, and J. Mumpower, p. 319-333. Plenum Press, New York City, New York.

Piatt, J. A. 1989. Articulation of Risk. Letter Report. Pacific Northwest Laboratory, Richland, Washington.

Ruckelshaus, W. D. September 1986. "Risk Communication: Why Is It So Tough to Discuss Risk with the Public?" Chemtech, pp. 533-535.

Rucke]shaus, W. D. 1985. "Risk, Science, and Democracy." Issues in Science and Technology 1(Spring):19-38.

Ruckelshaus, W. D. 1983. "Science, Risk, and Public Policy." Science 221():1026-1028.

Rycroft, R. W., J. L. Regens, and T. Dietz. 1987. "Acquiring and Utilizing Scientific and Technical Information to Identify Environmental Risks." Science, Technology and Human Values 12(Issues 3 and 4):125-130.

Sachsman, D. B. 1985. "Linking the Scientist and the Journal ist." HAZPRO ' 85 Professional Certification Symposium and Exposition, Baltimore, Maryland.

Samways, M. C. 1982. "Informing Those With a Need to Know." Journal of Occupational Medicine 24(5):387-392.

Sandman, P. M. 1987. "Explaining Risk to Non-Experts." Emergency Preparedness Digest, pp. 25-29.

Sandman, P. M. 1987. "Apathy Versus Hysteria: Public Perception of Risk." Public Perception of Biotechnology, pp. 219-231.

Sandman, P. M. 1987. "Risk Communication: Facing Public 0utrage." EPA Journal, pp. 21-22. 
Sandman, P. M. 1989. "Emerging Communication Responsibilities of Epidemiologist." Presented to the Conference on Ethics in Epidemiology. Industrial Epidemiology Forum. Birmingham, Alabama, June 12, 1989.

Sharlin H. I. 1986. "EDB: A Case Study in Communicating Risk." Risk Analysis 6(1):61-68.

Shaw, J. A., and J. Herb. October 1988. "Risk Communication: An Avenue for Public Involvement." Journal American Water Works Association, pp. 42-44.

Slovic, P. 1989. "Perception of Risk from Radiation." Proceedings of the 25th Annual Meeting of the National Council on Radiation Protection and Measurements. (In press).

Slovic, P. 1987. "Perception of Risk." Science 236(4699):280-285.

Slovic, P. 1986. "Informing and Educating the Public About Risk." Risk Analysis 6(4):403-415.

Slovic, P. 1982. Facts vs. Fears: Technical Risk Assessments and Public Perceptions. National Health Policy Forum, Washington, D.C.

Stallen, P. J. and R. Coppock. 1987. "About Risk Communication and Risky Communication." Letter to the Editor. Risk Analys is 7(4):413-414.

Thayer, A. M. 1989. "Alar Controversy Mirrors Differences in Risk Perceptions." Chemical and Engineering News. 67(35):7-14.

Trunk, A. D., and E. V. Trunk. 1983. "Impact of the Three Mile Island Accident as Perceived by Those Living in the Surrounding Community." The Analysis of Actual Versus Perceived Risks. ed. Covello, V. T., W. Flamm, J. Rodricks, and R. Tardiff, Plenum Press, New York, New York.

Weinberg, A. M. 1987. "Informing and Educating the Public About Risk," Letter to the Editor. Risk Analysis 7(3):281.

Weinstein, N. D., and P. M. Sandman. 1985. Recommendations for a Radon Risk Communication Program. Part 1 of the 0 ffice of Science and Research, New Jersey Department of Environmental Protection Report on a Risk Communication Symposium. Rutgers, The State University of New Jersey.

Wilson, R. 1979. "Analyzing the Daily Risks of Life." Technology Review, pp. 41-45

Wilson, R., and E. S. C. Crouch. 1987. "Risk Assessment and Comparisons: An Introduction." Science 236(4799):267-270. 


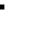


APPENDIX A

TSP DIRECTIVE 89-7, "PRESENTATION OF TECHNICAL MATERIAL TO THE PUBLIC" 


\section{TECHNICAL STEERING PANEL RESEARCH DIRECTIVE}

Directive Number:

Date:

Subject:
89-7

May 20, 1989

PRESENTATION OF TECHNICAL MATERIAL TO THE PUBLIC

\section{DISCUSSION:}

The Technical Steering Panel (TSP) recognizes that the characterization of uncertainty in dose estimates will be an essential result of the HEDR Project. A thorough and accurate accounting of uncertainties must be available to all interested persons. Such an accounting must be understood in order to be truly available. While scientific ar it technical audiences will be able to deal with information presented in a technical format, inte:csted lay persons will require clear, nontechnical explanations of the causes and magnitudes of uncertainties. An understanding of the causes of uncertainties is required for dose estimates and their uncertainties to be credible and to enhance the meaning and limiutions of dose estimates.

The TSP is responsible for selecting the methods that will be used to present information about HEDR results, including uncertainties, to the lay public. However, the TST recognizes that Battelle Pacific Northwest Laboratories (PNL) and the United States Department of Energy (DOE) may continue to be a source of this information after completion of the HEDR project. The TSP, therefore, needs to examine all possible methods fo: communication that might be used during and after the HEDR Project, in order to select mu:'hods that will be most effective.

\section{ACIION TO BE TAKEN:}

The TSP hereby directs the Battelle staff to investigate methens for presenting to the lay public information about both the causes and the magnitudes of unccrtainties in dose estimates. Past examples of communication of technical information to lay audiences, both by PNL and by other organizations, should be critically reviewed. In addition, PNL should seek out and consider innovative methods for such communication. Methods of cominunicating both to mass audiences and to individuals should be considered; the latter should include pe: sons for whom dose estimates are calculated.

Battelle is further directed to prepare a report of the investigation for delivery to the TSP no later than Febriary, 1990. This report should include descriptions of the methods of communication that are considered, along with critical evaluations of each method's cost and effectiveness.

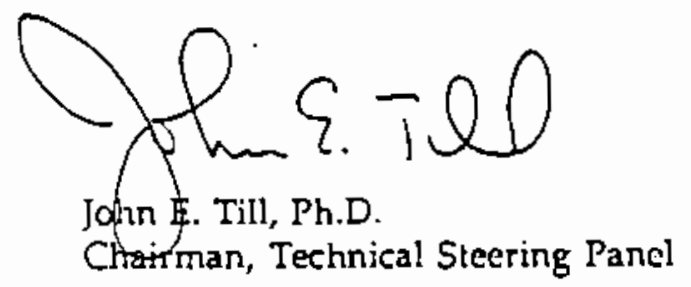




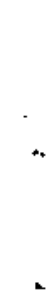


APPENDIX B

ANNOTATED BIBLIOGRAPHY 


\section{APPENDIX B}

\section{ANNOTATED BIBLIOGRAPHY}

The following is an annotated bibliography prepared during the course of the literature review. The annotated bibliography is included to add variety, depth, and relevance to this report. In many cases, these annotations supply supporting evidence and additional perspective. The annotated bibliography is separated into three main sections: risk analysis and communication (B.1), risk perception (B.2), and public involvement (B.3). Following each section is a listing of other relevant articles. The categorization of these articles was highly subjective, and like the summaries, was prepared with the applicability to the HEDR Project in mind. In addition, the summaries portray information relevant to the HEDR Project, so they may not include an entire representation of the article cited.

\section{B.1 RISK ANALYSIS AND COMMUNICATION}

Baybutt, P. 1989. "Communicating Risk, Step by Step." Hydrocarbon Processing (6):85-90.

Considerable research on risk communication had led to guidance on how to communicate risks. Seven cardinal rules on risk communication have been developed. These rules tell how to interact with the public and how to present information. While these rules provide valuable guidance, they should be used together with the judgment, intuition and experience of the communicator. Communication of risks is a complex and delicate task that calls on all resources of the communicator. Steps in a risk communications program are

1. Prepare the community: establish rapport.

2. Define the problem: why is risk communication necessary?

3. Formulate strategy: determine goals of communication, the types of information wanted, communication channels, and ways to express the risk. 
4. Collect information: perform a risk assessment, collect existing data, whatever is appropriate, prepare alternatives of actions citizens might take in reducing or controlling risk.

5. Prepare for communication: prepare and train speakers, pretest the message.

6. Make presentation: deliver the message and respond to objections.

7. Follow-up: negotiations, further data analysis, answer questions, repeat communications, evaluate and improve process.

Bean, M. C. February 1988. "Speaking of Risk." Civil Enqineering, pp. $59-61$.

Explaining risk to the public can be a relatively painless task for engineers who keep a few rules in mind. Because they understand what hazardous waste is, why it's harmful, and how to get rid of it, engineers often find themselves explaining risk to the public. However, there are some mistakes that are common. Engineers make comparisons among risks and use analogies thinking these "put risk in perspective." They use acronyms and jargon the public is probably not familiar with and tables and graphs prepared for technical reports. Each of these mistakes can impede an engineer's ability to describe risk effectively and earn public trust. What should risk communicators do?

Risk communicators should use a standard set of terms to minimize public confusion. Technical language, acronyms and jargon should be avoided. Tables and graphs should be simple and clear. Risk communicators will need to address four main questions from the public: was I exposed? how much? what are the effects? are you sure? The risk communicator must not shirk the responsibility of defining assumptions behind the analysis. Risk comparisons must be made carefully. In many cases, risk comparisons are so qualitatively different that they evoke outrage and hostility among the public. Some comparisons can be made between risks that the public sees as involuntary and similar in nature. 
Covello, V. T. and F. W. Allen. 1988. "Seven Cardinal Rules of Risk Communication." U.S. Environmental Protection Agency, Office of Policy Analysis, Washingtọn, D.C.

1. Accept and involve the public as a legitimate partner.

2. Plan carefully and evaluate your efforts.

3. Listen to the public's specific concerns.

4. Be honest, frank, and open.

5. Coordinate and collaborate with other credible sources.

6. Meet the needs of the media.

7. Speak clearly and with compassion.

Covello, V. T., D. von Winterfeldt and P. Slovic. 1987. "Communicating Scientific Information about Health and Environmental Risks: Problems and Opportunities from a Social and Behavioral Perspective." Uncertainty in Risk Assessment, Risk Management, and Decision Making. ed. Covello, V. T., L. Lave, A. Moghissi, and V. Uppuluri, pp. 221-239, Plenum Press, New York, New York.

Risk communication difficulties and frustrations are often a result of the problems and complexities of communicating health and environmental information in a pluralistic, democratic society. Depending upon the objective of the message, i.e. to inform, the characteristics of the communication problems vary. The communications process includes 1) the message, 2) the source, 3) the channel and 4) the receiver.

Message problems include:

- deficiencies in scientific understanding, data, models, and methods resulting in large uncertainties in risk estimates

- difficulties in assessing accident sequences, human exposures, synergistic effects, and consequences for sensitive populations such as children, pregnant women, and the elderly

- highly technical analyses that are often unintelligible to the average layperson. 
Source problems include:

- disagreements among scientific experts

- legal and resource constraints limiting the authority and actions of responsible officials

- gaps between societal-level, aggregate data and individual fears and concerns

- failures to disclose limitations of risk assessments and resulting uncertainties

- limited understanding of the interests, concerns, fears, values, priorities, and preferences of individual citizens and public groups

- use of bureaucratic, legalistic, and technical language

- lack of trust and credibility.

Channel problems include:

- selective and biased media reporting that emphasizes drama, wrongdoing, disagreements, and conflict

- premature disclosures of scientific information

- oversimplifications, distortions, and inaccuracies in interpreting technical risk information.

Receiver problems include:

- inaccurate perceptions of levels of risk

- lack of interest in risk problems

- overconfidence in one's ability to avoid harm

- strong beliefs and opinions that are resistant to change

- exaggerated expectations about the effectiveness of regulatory actions

- desire and demands for scientific certainty

- a reluctance to make trade-offs between different types of risks or between risks, costs, and benefits

- difficulties in understanding probabilistic information. 
Some conclusions include:

- The roots of most communication problems lie in the complexities of the risk problem itself. Communication problems can often be viewed as decision problems.

- Interactive and participatory approaches to risk communication appear to offer the greatest promise of better, less controversial, or less divisive decisions.

- There is no such entity as "the public." Instead, there are many publics, each with its own interests, needs, concerns, priorities and preferences.

- Government officials and individual citizens often hold different views of risk problems.

- In risk communication, one should 1) know the risk communication problem, 2) know the risk communication objectives, 3) use simple and non-technical language, and 4) listen to your audience and know their concerns.

Johnson, B. L. 1987. "Health Risk Communication at the Agency for Toxic Substances and Disease Registry." Guest Editorial. Risk Analysis $7(4): 409-412$.

Four areas for which the Agency for Toxic Substances and Disease Registry (ATSDR) has responsibility under Superfund are described in context of how each relates to risk communication. Four elements of risk communication are emphasized: a description of the activity, the message that is being communicated, the primary audience that is intended, and how risk gets communicated. The four responsibilities of ATSDR are described as health assessments, toxicological profiles, medical education and consultation, and exposure registries. The concluding five elements of successful communication are credibility, quality of the message, degree of involvement of the receiver, quality of the delivery, and evaluation of the outcome to improve future communications efforts.

Kasperson, R. E., "Six Propositions on Public Participation and Their ReTevance for Risk Communication," Risk Analysis, Vol. 6, No. 3, pp. 275-281, 1986. 
1. Conflicts emerging in public participation efforts often center upon means/ends differences in expectations.

2. Experience repeatedly demonstrates that a lack of early and continuing involvement is a characteristic source of failure for public participation programs.

3. The believability of risk information is closely related to institutional credibility and trust.

4. Effective public participation programs depends substantially upon the development of indigenous technical and analytic resource and upon institutional means to act upon increased knowledge.

5. Members of the public differ in arenas and scope of involvement, suggesting differing "thresholds" of involvement and differing communication strategies.

6. Although a large array of participation techniques exists, current knowledge does not allow for successful prediction as to which are likely to be effective under what conditions.

Additionally, public consideration of risk generally takes place in a social group rather than as an individual. Perceptions of the public as individuals are much better understood than as members of social groups.

Keeney, R. L. and D. von Winterfeldt. 1986. "Improving Risk Communication." Risk Analysis 6(4):417-424.

The communication of risks is a decision problem separate from the risk problem and its analysis. For any risk communication decision, it is useful to carefully spell out the communication objectives and list alternative strategies for achieving them. Some of the recommended strategies include

- Risk communicators should understand the public's individual and societal structures of risk problems and communicate within these structures. In addition, distinctions between these structures should be made clear.

- Technical and bureaucratic language should be avoided. Instead, people's concerns should be addressed in a framework using personal experiences which foster individual learning.

- An effort should be made to educate the public about the nature of risk and science. That is, there are no zero-risk solutions, tradeoffs are necessary, and uncertainty cannot be avoided. 
- To foster mutual learning between the public and the risk comnunicator, early public involvement is usually necessary.

- Efforts should be made to encourage the public to take personal risk reduction measures, if appropriate.

Konheim, C. S. 1988. "Risk Communication in the Real World." Risk Analysis $8(3): 367-373$.

Rigorous health risk assessments of site-specific projects are generally little understood by nontechnical decision makers and the public and often appear to them to obfuscate a straightforward answer to their fundamental question: "Is the project safe?" The focus on risk, usually out of context of benefits, deprives the reader of the opportunity to make a fully informed decision on the proposal. While the risk assessment tools may need to be refashioned, confidence in the analytical process can be improved, partly through more citizen involvement, as well as through more effective communication of the conservatism of the assumptions, the thoroughness of the process, and the significance of the results in comparison to other commonly accepted involuntary exposures and risks.

There are steps to improve communications of a standard risk assessment. The first step is to build trust in the individuals who are undertaking the analysis and in their assumptions, preferably through a citizens' oversight mechanism. The second step is to put the results into perspective through discussions of comparative courses of action. A third measure is to ensure that the study is accompanied by an executive summary that will enable the nontechnical reader to follow the assumptions and methodology of the study as well as its conclusions. A fourth is to assure that the media are well briefed and provided with concise materials.

Mumpower, J. L. 1988. "Lottery Games and Risky Technologies: Communications About Low-Probability/High-Consequence Events." Risk Analysis $8(2): 231-235$.

Risk communication is an issue of pressing importance. As a society, we have only a few years' experience in communicating about low-probability, high-consequence technological hazards. Opportunities exist to learn valuable lessons from other areas by extension or analogy. Lotteries possess 
strong structural similarities to the types of risks about which we wish to find better ways to communicate. Typical communications about state lotteries provide a virtual strategic textbook for opponents of risky technologies. Eight basic principles are enumerated: 1) emphasize consequences, 2) express consequences in terms of nondiscounted rather than net present values, 3) ignore probabilities, 4) emphasize absolute frequencies rather than base rates, 5) present detailed, vivid information about specific instances of extreme outcomes, 6) repeat the presentation of detailed case information frequentiy, 7) focus on the most extreme consequences of the probability distribution, and 8) look for situational factors that can influence individuals' behavior.

National Research Council. 1989. Improving Risk Communication. National Academy Press, Washington, D.C.

A successful risk communication program will raise public understanding of relevant issues and enable the public to feel sufficiently informed within the limits of available knowledge. This is contrary to a common definition of successful risk communication, that is, when the audience accepts the views of the communicator as "correct." In addition, risk communication should establish a dialogue, a two-way interactive communication, with interested publics to deal with problems and misunderstandings early. There are problems with risk communication, however.

Problems deriving from institutional and political systems are problems for which little can done--beyond trying to understand them--by those involved in risk communication. Nevertheless, these problems can have a considerable impact on actions and events. Problems of risk communicators and recipients can be addressed more directly and are therefore more amenable to improvement or solution.

Examples of institutional problems might include legal constraints, divided authority among government agencies, increased desire of citizens to influence risk decisions, and systematic biases in the provision of information. Problems of risk communicators and recipients include lack of credibility, use of appropriate language (technical vs. non-technical), drawing 
conclusions from incomplete data, and information acquisition and distribution. While these problems are a challenge, the study also developed recommendations suggesting that will help address risk communication problems.

The conclusions and recommendations were formulated with the assumptions that the risk message will be intended for a non-technical audience and the risk-managing bodies will be government agencies and large private corporations. The three major conclusions include

1. Even great improvement in risk communication will not resolve risk management problems and end controversy (a)though poor risk communication can create them). Because risk communication is so tightly linked to the management of risks, solutions to the problems of risk communication often entail changes in risk management and risk analysis. There is unfortunately, no ready shortcut to improving the nation's risk communication efforts. The needed improvement in performance can only come incrementally and only from assiduous attention to detail.

2. Solving the problems of risk communication is as much about improving procedures as improving content. Risk managers need to consider risk communication as an important and integral aspect of risk management. In some instances, risk communication will, in fact, change the risk management process itself.

3. Two broad themes are apparent in the extended list of recommendations: the communications efforts should be more systematically oriented to specific audiences and that openness is the surest policy. In other words, the most effective risk messages will self-consciously address the audiences' perspectives and concerns in an open way.

Again, risk communication can only be successful if it improves or increases the base of accurate information that decision makers use, be they government officials, the public, or industry managers. Under this premise, four recommendations evolved from the study:

1. recommendations for the processes by which organizations generate decisions, knowledge, and risk messages, including discussions on goal setting, openness, balance and accuracy, competence, and communicating in crisis situations

2. recommendations for the content of the risk message, including discussions on audience orientation, uncertainty, risk comparisons, and completeness 
3. a call for a "consumer's guide" to help others become involved in risk management activities

4. a summary of additional research needs.

Included in Appendix $C$ is a description of controversies in which risk perception and risk communication play significant roles. Understanding the role of risk communication, given appropriate objectives and realistic expectations, is essential to the risk communication program. More importantly, the roles and perceptions of the players must be considered to formulate an effective risk communication program. Topics include the realities and expectations of science and policy, the nature of the controversy between experts and lay people, strategies for risk communication, and psychological principles in communication design. This appendix is oriented toward a more practical application of risk communications.

Otway, H. 1987. "Experts, Risk Communication, and Democracy." Risk Analysis $7(2): 125-129$.

Recognizing there are 1 imitations of experts (perceived and real) in assessing technologies, the public increased its participation in technological decision making. The public will no longer accept risk as defined by quantitative criteria alone. After all, the true experts on questions of value regarding the risks of technology are the people whose lives are affected.

Risk communication establishes dialogue--we are ready to talk and, presumably, to listen as well. Democratic communication will give people information so they can form their own opinions, rather than persuade people to accept a decision or policy. It is a matter of intent: public empowerment or manipulation.

Risk communication can begin by acknowledging limits to expertise, discussing uncertainty, alternative interpretations, peer review, and how research strategies are evolved and funded. Let the public be a resource. 
Our goal should be to help develop an informed public, able to recognize and respect genuine scientific competence and integrity, prepared to contribute effectively to decision making.

Ruckelshaus, W. D. 1983. "Science, Risk, and Public Policy." Science 221(): 1026-1028.

A $c l$ imate of fear now dominates the discussion of environmental issues. The scientific community can help alleviate this fear by making a greater effort to explain to the public the uncertainties involved in estimates of risk. Current statutory mandates designed to protect public health both demand levels of protection that technology cannot achieve and are uncoordinated across government agencies. A common statutory framework for dealing with environmental risks is needed. In addition, care must be taken to separate the scientific process of assessing risk from the use of such assessments, together with economic and policy considerations, in the management of risks through regulatory action.

Science thrives on uncertainty. The public expects, and sometimes demands, certainty. Thus, scientists must be willing to take a larger role in explaining scientific realities of risks to the public--including the uncertainties inherent in any risk assessment. What we need to hear more of from scientists is science. And, rather than denigrate people's perceived risks, we must seek to inform their discretion.

Sachsman, D. B. 1985. "Linking the Scientist and the Journalist." HAZPRO ' 85 Professional Certification Symposium and Exposition, Baltimore, Maryland.

Scientists and journalists have very little in common. Although both attended college, they generally sat in different classrooms. While scientists were becoming specialists, journalists were becoming generalists.

To journalists, scientists are news sources, just like politicians, educators, police officers, and fire fighters. Reporters approach sources for specific information. They usually don't want any more than they ask for, and they rarely are interested in hearing about anything other than the story they are working on. Journalists sometimes leave the impression that they think they know it all. News sources, and especially scientists, 
sometimes try to "teach" reporters what is "really" important. When both things happen at the same time, the result may be an adversary relationship.

Some scientists are willing to admit that they are often confounded and occasionally annoyed by journalists, but few blame their irritation on their own lack of understanding of the news business. Scientists are the best and brightest--why shouldn't they understand journalists?

Real understanding implies empathy, the ability to identify with the feelings, thoughts or attitudes of others. One solution for gaining enpathy is the staging of an environmental crisis for journalists and scientists. A panel of experts serve as news sources, and a panel of journalists are assigned to cover the story. Assuming they all have the interest of the public at heart, the end result is not only knowledge but understanding and identification. It gives everyone involved and everyone watching a chance to see how the various people think and act. This is beneficial for experts as well as journalists. This technique not only clarifies the substantive issues involved, but it also gives insight into the decision-making processes of both journalists and experts.

Samways, M. C. 1982. "Informing Those With a Need to Know." Journal of Occupational Medicine 24(5):387-392.

The issue of informing employees, customers, government agencies and other about health hazards in and out of the workplace is important. Once it is established that there is a hazard, the primary purpose of communication is to provide those who need to know with comprehensible and effective information about the nature of the hazard, and how to protect themselves from these hazards and potential risks.

Simply transmitting the message does not mean the receiver comprehends. In fact, attention tends to focus on the accuracy of the scientific data at the expense of comprehension of the hazard and knowledge of the appropriate responses. First, who needs to know? Information must be given to all those affected. Second, what constitutes comprehensible information?

Comprehensible information can be measured by an increase in knowledge, an increase in skills, or a change in behavior. Fire drills, for instance, 
teach people appropriate behaviors in an emergency. Passive information systems, such as a lecture, are generally less effective than an active system, such as the fire drill. Finally, protection involves the identification and implementation of actions that can be taken to reduce or eliminate potential hazard situations. Part of this may include frequent updates of comprehensible information.

Sandman, P. M., "Emerging Responsibilities of Epidemiologist, " presented to the Conference on Ethics in Epidemiology, Industrial Epidemiology Forum, Birmingham, AL, June 12, 1989.

Epidemiologist are increasingly called upon to comunicate with affected publics when designing, interpreting, and reporting their work. The author offers eight guidelines for public communication:

1. Tell the people who are most affected what you have found--and tell them first.

2. Make sure people understand what you are telling them (simplification), and what you think its implications are (interpretation).

3. Develop mechanisms to bolster the credibility of your study and your findings.

4. Acknowledge uncertainty promptly and thoroughly. The comunity may tend to dichotomize the science--is it certain (good science) or is it not certain (bad science). The key is to begin building realistic expectations.

5. Apply epidemiological expertise where it is called for, and do not misapply it where it is unlikely to help.

6. Show respect for public concerns even when they are not "scientific." Listen to people's anecdotal evidence, and their concerns which may foster outrage--it's a broader definition of risk than simply looking at the technical data.

7. Involve people in the design, implementation, and interpretation of the study. Consider the advantages of establishing a dialogue:

A) People will have an easier time knowing and understanding what you found because they will have helped you find it. B) People will see your results as more credible because they will have had sufficient involvement to trust the findings without relying blindly on your integrity, and sufficient contact to build some trust in your integrity. C) People will have considered in advance what an alarming outcome and a reassuring outcome might look like in data terms, and thus will have a clear assessment of the extent 
to which the study can help resolve the questions that concern them and D) People will have had a chance to absorb technical concepts like case control research, statistical significance, and quantitative risk assessment, making your reliance on these concepts less alienating.

8. Decide that communication is part of your job, and learn the rudiments--it's easier than epidemiology.

Sharlin, H. I. 1986. "EDB: A Case Study in Communicating Risk." Risk Analysis 6(1):61-68.

This is a report on the Environmental Protection Agency's (EPA's) efforts to communicate with the public about the risks of ethylene dibromide (EDB), what the agency said it was doing about these risks and what information the public actually received through television and newspapers. Although special in many ways, the EDB case jllustrates the problems that regulatory agencies have when they must take regulatory action and assure the public that the risks in questions are being dealt with adequately. It also illustrates issues that the press faces. Above all, it illustrates the barriers to comunication presented by the different perspectives of regulatory agencies and individuals and the types of information they each are most interested in.

of note are the ways the message was transmitted. The major impact that the television medium had on the public microrisk perception was in the creation of dramatic images and the lack of subtlety. The national newspapers, generally, dealt with macrorisk issues and were consistently more accurate and detailed than local newspapers on technical questions. This was to be expected since larger newspapers have specialized staffs of sciences writers, as well as better access to expert information than do small local papers. The local papers had to translate EPA information into something newsworthy and local in interest. The results ranged from concern for adverse effects on local growers to cancer concerns of local populations.

In conclusion, agencies must often play dual roles. The first role is to make decisions about allowing or prohibiting and in setting standards. In the process, the public's views and comments must be considered. The second 
role is public information. Agencies must learn to distinguish between and manage both macrorisk (societal risk) and microrisk (individual risk).

Slovic, P. 1986. "Informing and Educating the Public About Risk." Risk Analysis. $6(4): 403-415$.

The objective of informing and educating the public about risk issues seems easy to attain in principle, but in practice, may be difficult to accomplish. This paper attempts to illustrate why this is so. To be effective, risk communicators must recognize and overcome a number of obstacles that have their roots in the limitations of scientific risk assessment and the idiosyncracies of the human mind. Doing an adequate job of communicating means finding comprehensible ways of presenting complex technical material that is clouded by uncertainty and inherently difficult to understand. The problems may not be insurmountable, however, if designers of risk information programs are sensitive to the difficulties.

It appears that people understand some things quite well, although their path to knowledge may be quite different from that of the technical experts. In situations where misunderstanding is rampant, people's errors can often be traced to biased experiences, which education may be able to counter. In some cases, people's strong fears and resistance to experts' reassurances can be traced to their sensitivity to the potential for catastrophic accidents, to their perception of expert disagreement about the probability and magnitude of such accidents, to their knowledge of serious mistakes made by experts in the past, and to their sensitivity to many qualitative concerns, not included in the quantitative analysis. Given an atmosphere of trust in which both experts and laypersons recognize that each group has something to contribute to the discussion, exchange of information and deepening of perspectives may well be possible.

Stallen, P. J. and R. Coppock. 1987. "About Risk Communication and Risky Communication." Letter to the Editor. Risk Analysis 7(4):413-414.

Risk communication is becoming a central feature of public policy as it is related to technological hazards. Risk communication can be distinguished by four imperatives: persons at risk ought to be informed, citizens have a 
right to information, people want information, and the public wants to be reassured with information that risks are being handled efficiently and effectively.

Considerations must also be given to practical aspects of risk communication such as when to communicate, what the content should be, and how communication should be carried out. These considerations, however, result in conflicting recommendations on risk communication. On one hand, one set of recommendations embody the imperatives of a more idealistic nature. On the other hand, the concerns of practitioners are reflected.

Thayer, A. M. 1989. "Alar Controversy Mirrors Differences in Risk Perceptions." Chemical and Engineering News. 67(35):7-14.

Avoiding future batties over chemicals as contaminants in food supply, such as that involving growth regulator Alar, will require bridging gaps in risk communication among industry, government, and the public. Bridging these gaps will require companies to establish dialogue. Dialogue is a twoway communication with the public in which the company learns to listen, to understand concerns, to explain data, to share control, to involve the public in decision-making, and to reach better decisions. Although there is a need for technical data to be provided and explained carefully so that it can be understood, doing so does not mean that the public will end up with the same views or make the same decisions as industry or government.

It is important to get the representatives of a company identified, get them accustomed to working together, and have a sense of the composition and leadership of the team. At the same time, each of these people should be gathering information as to public concerns or questions. When it comes to providing information, it is better to present whatever is available, even if incomplete, and to continue to make facts public as they become known. Additionally, a company should not necessarily devote maximum resources to attacking their strongest opposition. Those opinions probably won't change. Therefore, a more successful communications strategy may be developed by 
managing the flow of data, identifying knowledgeable and credible third parties as sources of information, and working with what probably will be a larger group of undecided people.

Wilson, R., and E.S.C. Crouch. 1987. "Risk Assessment and Comparisons: An Introduction." Science 236(4799):267-270.

Risk assessments, except in the simplest of circumstances, are not designed for making judgments, but for illuminating them. Risk assessments are performed to estimate probabilities for various events, usually injurious. Different uncertainties describing a risk are part of a risk assessment. One part of the risk is stochastic (how does the individual behave to put himself at risk). Another part is systematic (what is the nature of the hazard). Estimates of these risks can be largely subjective, with differences of opinion rising from the assignment of uncertainty.

The purpose of risk assessment is to be useful in making decisions about the hazards causing risks. It is important to gain some perspective about the meaning of the magnitude of the risk. Comparisons can be useful.

The way in which risks are perceived is strongly correlated with the way in which they are calculated. There are several methods of comparison. Risks based on historical data are more easily understood and are often perceived reliably. An example is a comparison of several common radiation risks.

Another method of risk comparison is risk by analogy. This is appropriate when little historical data exist and the risk is small (an example might be cancer: there is a time delay between the insult and the final cancer). The analogy might be done with cancer risks to animals, other analogies can be based on chemical similarity, and comparisons with outcomes other than cancer, i.e., mutagenesis, acute toxicity, and heart disease.

Yet a third method might be comparing the risk value against the certainty of information. After risks of a number of situations have been assessed, we often want to order them to decide which should command our 
attention. It is not aiways the order of increasing risk that is used for such purposes. There have been proposals to order potential carcinogens on other factors such as the certainty of information.

Contrasting risks is still another method of comparison. Objections have been raised to risk comparisons on the ground that they are misleading. This would be true if all risks of the same numerical magnitude were treated in the same way. But they are not. In some cases it is useful to contrast risks to indicate the different ways in which they are treated in society.

A careful selection of the methods to express risk is just as important as a comparison of risks is an aid in understanding them. It is hard to comprehend the statistical nature of risk. One way to mitigate this difficulty is to use the expectation of life. The expression of risk in terms of reduction in life expectancy can helpful because it is easy to remember.

Another way of comparing risks is by comparing the amount people have paid in the past to reduce them. Society is willing to spend more on environmental protection to prevent cancer (over $\$ 1$ million per life) than on cures (about $\$ 50,000$ per life with the high value of $\$ 200,000$ for kidney dialysis, raising some objections). This ratio is in rough accord with the maxim "an ounce of prevention is worth a pound of cure."

All of these methods help clarify risk assessments in providing information to a decision-maker and can well be essential for an informed decision. A full understanding of risk involved is more likely when it is expressed in as many different ways as possible.

\subsubsection{Other Relevant Articles on Risk Analysis and Communication}

American Chemical Society Working Group on Risk Communication. 1988. "Chemical Risk Communication: Preparing for Community Interest in Chemical Release Data." American Chemical Society, Washington, D.C.

Bick, T., C. Hohenemser and R. W. Kates. 1979. "Target: Highway Risks." Environment. 21(2):7-15, 29-38.

Britain, V. A. September 1974. "Radiation: Benefit vs. Risk." FDA Consumer. 
Chess, C. 1987. "Encouraging Effective Risk Communication in Government: Suggestions for Agency Management." Environmental Communication Research Program, New Brunswick, New Jersey.

Chess, C, and B. J. Hance. 1989. "Making Risk Communication Agency Reality." Environment 31(5):11-39.

Cohen, B. L. and I. Lee. 1978. "A Catalog of Risks." Health Physics $36(6): 707-722$.

Cove110, V. T., P. M. Sandman and P. Slovic. 1988. Risk Communication, Risk Statistics, and Risk Comparisons: A Manual for Plant Managers. Chemical Manufacturers Association, Washington, D.C.

Davies, C. J. and V. T. Covello. 1986. "Risk Communication." Proceedings of the National Conference on Risk Communication. Conservation Foundation, Washington, D.C.

Environmental Protection Agency (U.S.). 1987. Risk Assessment, Management, Communication: A Guide to Selected Sources, Update. National Technical Information Services, Washington, D.C.

Forscher, F. 1986. "Understanding Risks." Hazard Prevention (Juiy/August) : 26-28.

Hance, B., C. Chess and P. M. Sandman. 1988. Improving Dialogue With Communities: A Risk Communication Manual for Government. New Jersey Agricultural Experiment Station, Cook College, Rutgers University, New Brunswick, New Jersey.

Hohenemser, C., R. Goble, J. X. Kasperson, R. E. Kasperson, R. W. Kates, P. Collins, A. Goldman, P. Slovic, B. Fischhoff, S. Lichtenstein, and M. Layman. 1986. "Methods for Analyzing and Comparing Technological Hazards." Risk Evaluation and Management, ed. Covello, V. T., J. Menkes, and J. Mumpower, pp. 249-274. Plenum Press, New York, New York.

Johnson, R. 1986. "EDB (Ethylene Dibromide)." Summary of Panel Discussion. Proceedings of the National Conference on Risk Communication, ed. Davies, C. J. and V. T. Covello, pp. 83-85. Conservation Foundation, Washington, D.C.

Kamrin, M. A. 1987. "Communicating Risk Assessment to the Public." Letter to the Editor. Environmental Toxicology and Chemistry 6:85-87.

Kasperson, R. E. 1986. "Six Propositions on Public Participation and Their Relevance for Risk Communication." Risk Analysis 6(3):275-281. 
Krimsky, S, and A. Plough. 1988. Environmental Hazards: Communicating Risks as a Social Process. Auburn House Publishing Company, Dover, Massachusetts.

Michaud, G. R. 1989. "Accepting New Technology: Community Relations for Mobile Incineration in Illinois." Presented at the Risk Analys is Conference, October 30, 31, and Novembér 1, 1989, San Francisco, California.

National Research Council. 1982. Risk and Decision Making: Perspectives and Research. National Academy Press, Washington, D.C.

Nealey, S. M., and E. B. Liebow. 1988. Assessing Social and Economic Effects of Perceived Risk: Workshop Summary. PNL-6515, Pacific Northwest Laboratory, Richland, Washington.

Otway, H. and B. Wynne. 1989. "Risk Communication: Paradigm and Paradox." Risk Analysis 9(2):14l-145.

Philipson, L. L. 1986. "Risk Evaluation: A Review of the Literature." Risk Evaluation and Management, ed. Covello, V. T., J. Menkes, and J. Mumpower, p. 319-333. Plenum Press, New York City, New York.

Piatt, J. A. 1989. Articulation of Risk. Letter Report. Pacific Northwest Laboratory, Richland, Washington.

Ruckelshaus, W. D. September 1986. "Risk Communication: Why Is It So Tough to Discuss Risk with the Public?" Chemtech, pp. 533-535.

Rycroft, R. W., J. L. Regens, and T. Dietz. 1987. "Acquiring and Utilizing Scientific and Technical Information to Identify Environmental Risks." Science, Technology and Human Values 12(Issues 3 and 4):125-130.

Sandman, P. M. 1987. "Explaining Risk to Non-Experts." Emergency Preparedness Digest, pp.25-29.

Sandman, P. M. 1987. "Apathy Versus Hysteria: Public Perception of Risk." Public Perception of Biotechnology, pp. 219-231.

Sandman, P. M. 1987. "Risk Communication: Facing Public Outrage." EPA Journal, pp. 21-22.

Weinberg, A. M. 1987. "Informing and Educating the Public About Risk," Letter to the Editor. Risk Analys is $7(3): 281$.

Weinstein, N. D., and P. M. Sandman. 1985. Recommendations for a Radon Risk communication Program. Part 1 of the Office of Science and Research, New Jersey Department of Environmental Protection Report on a Risk Communication Symposium. Rutgers, The State University of New Jersey.

Wilson, R. 1979. "Analyzing the Daily Risks of Life." Iechnology Review, pp. 41-45 


\section{B.2 RISK PERCEPTION}

Fischhoff, B., P. Slovic and S. Lichtenstein. 1982. "Lay Foibles and Expert Fables in Judgments about Risk." The American Statistician 36(3)2:240-255.

Public perceptions of risk are a focal point of many debates about the management of hazardous technologies. Different views about what the public knows and wants often lead to quite different beliefs about what policies should be adopted and even about how society's policy-making process should be structured. Often these views about the public are based on speculation or anecdotal observation. In the interests of having better informed debates, the present paper reviews existing empirical evidence about public risk perceptions. In doing so, it reaches a number of interim conclusions and draws forth their implications of the respective roles of technical experts and lay people in technology management. Some of the main conclusions presented in this paper include

- Examining behavior systematically yields some surprises, i.e., casual observations cannot be presumed to be valid. Such theories are often poorly formulated, based on scanty or poorly sampled evidence and insensitive to inconsistent data.

- Studying behavior is difficult. The fact that one has a question is no guarantee that others have answers, or even that they have devoted any prior thought to the matter. One cannot claim to be serving respondents' best interest by asking a question that oniy touches one facet of a complex set of views.

- Lay people are not stupid or irrational. Sometimes people's perceptions of risk are inaccurate or erroneous, but are seldom stupid or irrational.

- Even when lay people seem to be badly confused, their behavior may still be quite reasonable. Failure to understand implies that had people been provided with better information, their performance would be better. The source of much technical information is the technical community. There are a number of ways in which the experts fail, either deliberately or inadvertently, to inform the public.

- Experts are fallible too. When forced to go beyond the 1 imits of the available data or to convert their incomplete knowledge into judgments usable by risk assessors, experts may fall back on intuitive processes, just like everyone else. 
Friedman, R. 5. 1989. "Dealing With Public Perceptions of Health Risks in a Nuclear World." Nuclear Plant Journal 7(2):66-75.

It is hard to change people's minds when they have a firm belief (i.e., that nuclear power is dangerous).

Lack of volunteerism, delay in effect, limited knowledge and understanding of the risk, lack of control and especially fear of catastrophe are all associated with nuclear accidents and all were found to reduce the willingness of respondents to accept the risk associated with the technology. In addition, natural hazards appear to be more acceptable to people than those that are manmade. Large segments of the public do not separate the risks associated with nuclear energy from those identified with nuclear warfare. Slovic.

Recognizing that enormous gaps exist between the perceptions of the technical community and the public at large, one measure that can be taken to narrow this gap is risk communication. Education of relative risk probabilities associated with different technologies is important.

Another measure is to examine risks and benefits in a context that recognizes a vast array of divergent values within the population.

Yet another measure is to interact often with the public during the decision making processes. Openness is the hallmark of increased trust.

A process must be developed that considers both expert analysis and public reaction.

Kasperson, R. E., 0. Renn, P. Slovic, H. S. Brown, J. Emel, R. Goble, J. X. Kasperson, and S. Ratick. 1988. "The Social Amplification of Risk: A Conceptual Framework." Risk Analysis 8(2):177-197.

"One of the most perplexing problems in risk analysis is why some relatively minor risks or risk events, as assessed by technical experts, often elicit strong public concerns and result in substantial impacts upon society and economy. This article sets forth a conceptual framework that seeks to link systematically the technical assessment of risk with psychological, sociological, and cultural perspectives of risk perception and risk-related behavior. The main thesis is that hazards interact with psychological, 
social, institutional, and cultural processes in ways that may amplify or attenuate public responses to the risk or risk event.

A structural description of the social amplification of risk is now possible. Amplification occurs at two stages: in the transfer of information about the risk and in the response mechanisms of society. Signals about risk are processed by individual and social amplification stations, including the scientist who communicates the risk assessment, the news media, cultural groups, interpersona] networks, and others. Key steps of amplifications can be identified at each stage. The amplified risk leads to behavioral responses, which, in turn, result in secondary impacts. Models are present that portray the elements and linkages in the proposed conceptual framework."

\section{B.2.1 0ther Relevant Articles in Risk Perception}

Fischhoff, B., S. Lichtenstein, P. Slovic, S. L. Derby and R. L. Keeney. 1981. Acceptable Risk. Press Syndicate of the University of Cambridge. New York, New York.

Fischhoff, B., P. Slovic and S. Lichtenstein. 1983. "'The Public' vs. 'the Experts': Perceived vs. Actual Disagreements about Risks of Nuclear Power." The Analysis of Actual Versus Perceived Risks. ed. Covel lo, V. T., Flamm, W., Rodricks, J., and Tardiff, R., Plenum Press, New York, New York.

Kraft, Michael E. 1989. Risk Perception and the Politics of Citizen Participation: The Case of Radioactive Waste Management. Presented at the Risk Analys is Conference, October 30, 31, and November 1, 1989, San Francisco, California.

Litai, D., D. D. Lanning, and N. C. Rasmussen. 1983. "The Public Perception of Risk." The Analysis of Actual Versus Perceived Risks. ed. Covello, V. T., W. G. Flamm, J. Rodricks, and R. Tardiff, Plenum Press, New York, New York.

Slovic, P. 1989. "Perception of Risk from Radiation." Proceedings of the 25th Annual Meeting of the National Council on Radiation Protection and Measurements. (In press)

Slovic, P. 1987. "Perception of Risk." Science 236(4699):280-285.

Slovic, P. 1982. Facts vs. Fears: Technical Risk Assessments and Public Perceptions. National Health Policy Forum, Washington, D.C. 
Trunk, A. D., and E. V. Trunk. 1983. "Impact of the Three Mile Island Accident as Perceived by Those Living in the Surrounding Community." The Analysis of Actual Versus Perceived Risks. ed. Covello, V. T., W. Flamm, J. Rodricks, and R. Tardiff, Plenum Press, New York, New York.

\section{B.3 PUBLIC INVOLVEMENT}

Desvousges, W. H., and V. K. Smith. 1988. "Focus Groups and Risk Communication: The "Science" of Listening to Data." Risk Analysis 8(4):479-484.

Focus groups are becoming an important technique in understanding how people respond to environmental risk. Focus groups offer insights that can make risk communication more effective by helping communicators listen to "consumers" of risk messages. Specific roles of focus groups in risk communication might include

- exploring risk perceptions

- evaluating perceptual cues and information processing

- pretesting risk-communication materials

- selecting risk-comnunication channels

- designing risk-mitigation policies

- assessing risk-communication effectiveness.

Also offered are some rules of thumb on implementing focus groups, based on the authors' experience. For example, their advice is to keep the group sma11, make sure the moderator is represented as a nonexpert in the risk area, and select a relaxed setting.

Shaw, J. A., and J. Herb. October 1988. "Risk Comunication: An Avenue for Public Involvement." Journal American Water Works Association, pp. 42-44.

Government environmental agencies have an opportunity to find solutions to environmental health risks that satisfy both agency requirements and public concerns. Previous efforts have concentrated on educating citizens about technical aspects in hopes that the public will "see the 1ight" and support agency decisions. Many agency staff members believe that citizens will immediately embrace agency regulatory efforts if staff can just find one 
magical way to explain parts per billion. In truth, however, no amount of one-way education can substitute for two-way dialogue.

\section{B.3.1 Other Relevant Articles on Public Involvement}

Dietz, T., P. Stern and R. Rycroft. 1989. "Definitions of Conflict and the Legitimation of Resources: The Case of Environmental Risk." Sociological Forum 4(1):47-70.

Gundry, K. G., and T. A. Heberlein. 1984. "Do Public Meetings Represent the Pub]ic?" APA Journal, Spring, pp. 175-182.

Heberlein, T. A. 1976. Principles of Public Involvement. Department of Rural Sociology, University of Wisconsin-Madison, Madison, Wisconsin.

Ruckelshaus, W. D. 1985. "Risk, Science, and Democracy." Issues in Science and Technology l(Spring): $19-38$. 

APPENDIX C

METHODS FOR EXPLAINING TECHNICAL INFORMATION 


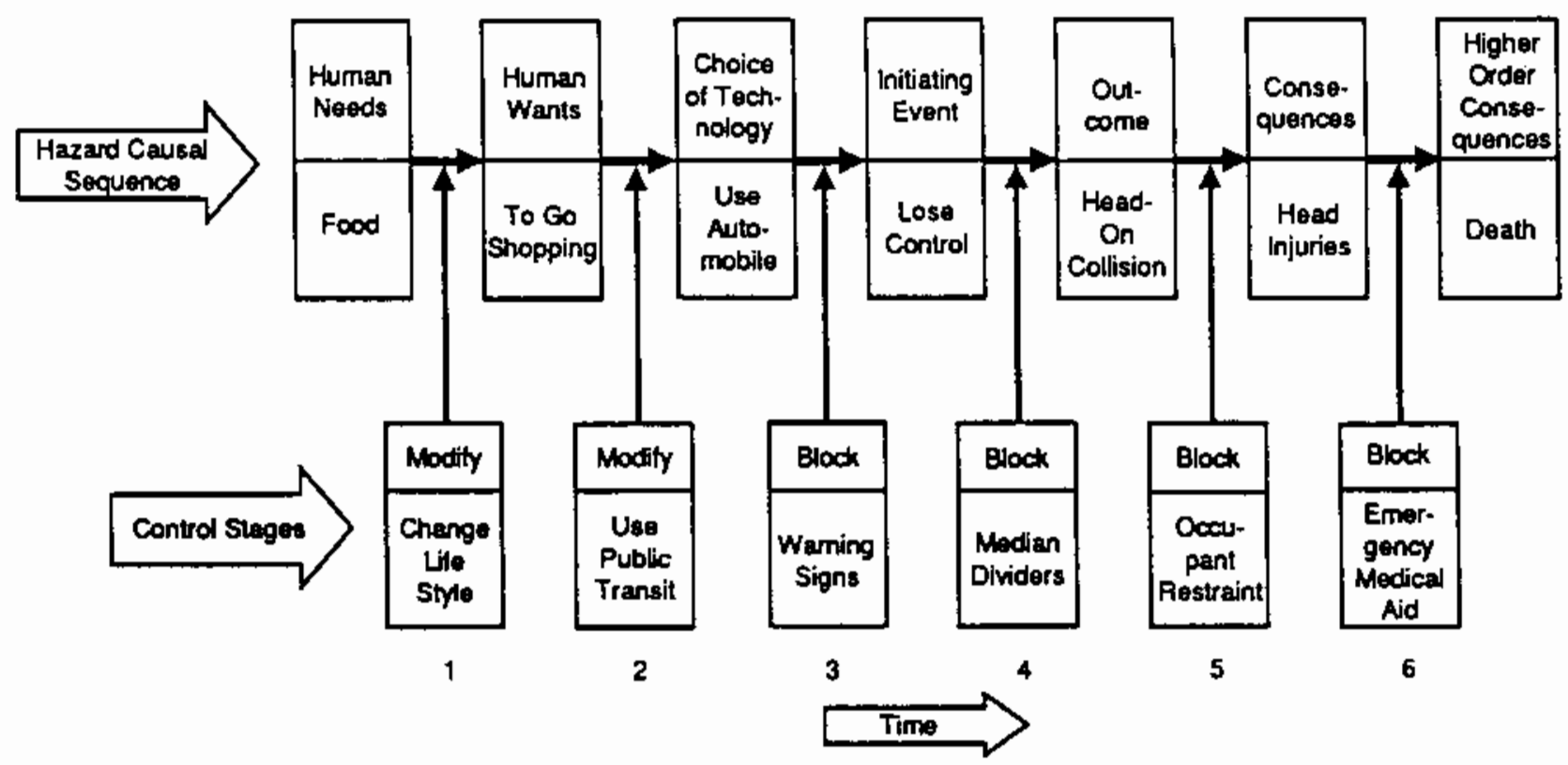

The causal chain of hazard evolution. The top line indicates seven stages of hazard development, from the earliest (left) to the final stage ( $r i g h t$ ). These stages are expressed generically in the top of each bax and in terms of a sample notor vehicle accident in the bottom. The steges are linked by causal pathways denoted by triangles. Six control steges are linked to pathways between hazard stotes by vertical arrous. Each is described genericalty as well as by specific control actions. Thus control stage 2 would read: "You cen modify technology choice by substituting public transit for autanobile we and thus block the further evolution of the motor vehicle accident sequence arising aut of autombile use." The time dimension refers to the ordering of a specific hazard sequence; it does not necessarily indicete the tiane scale of managerisl action. Thus, from a managerial point of vien, the occurrence of certain hazard consequences moy trigger control actions that offect events earlier in the hazard sequences.

FIGURE C.1. The Causal Model (National Research Council, 1989. Used with permission, original source: Figure - Bick 1979; Caption - Fischhoff, et al. 1981.) 


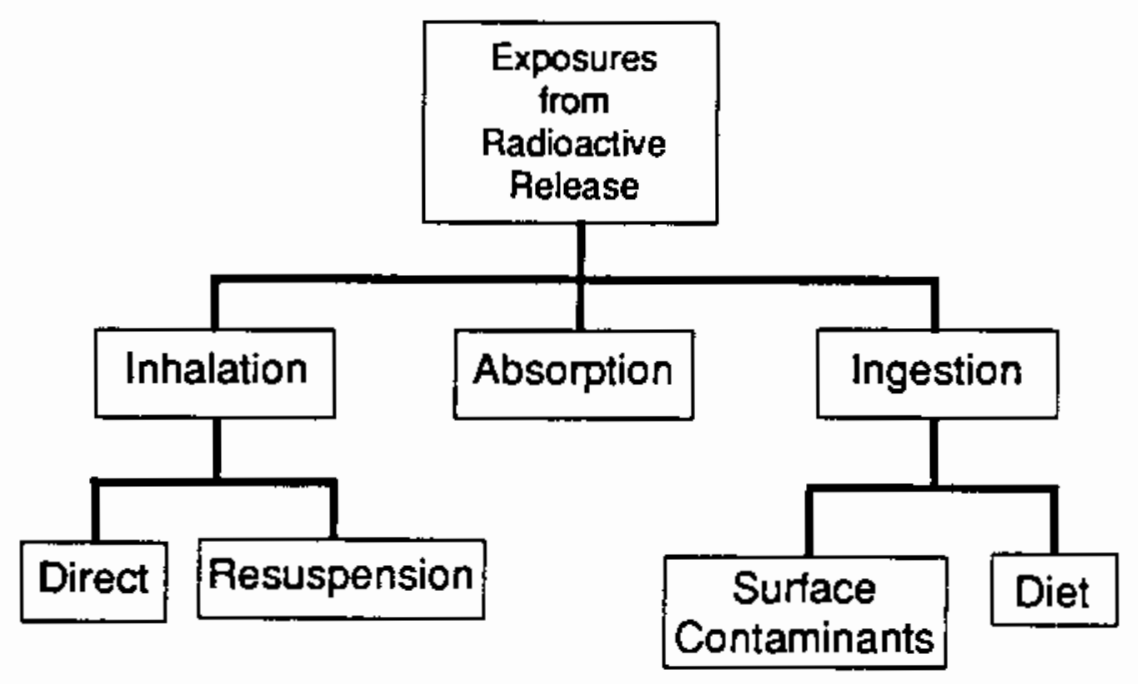

$\$ 9001023$

FIGURE C.2. The Fault Tree 
Nuclear Fuel Logistics

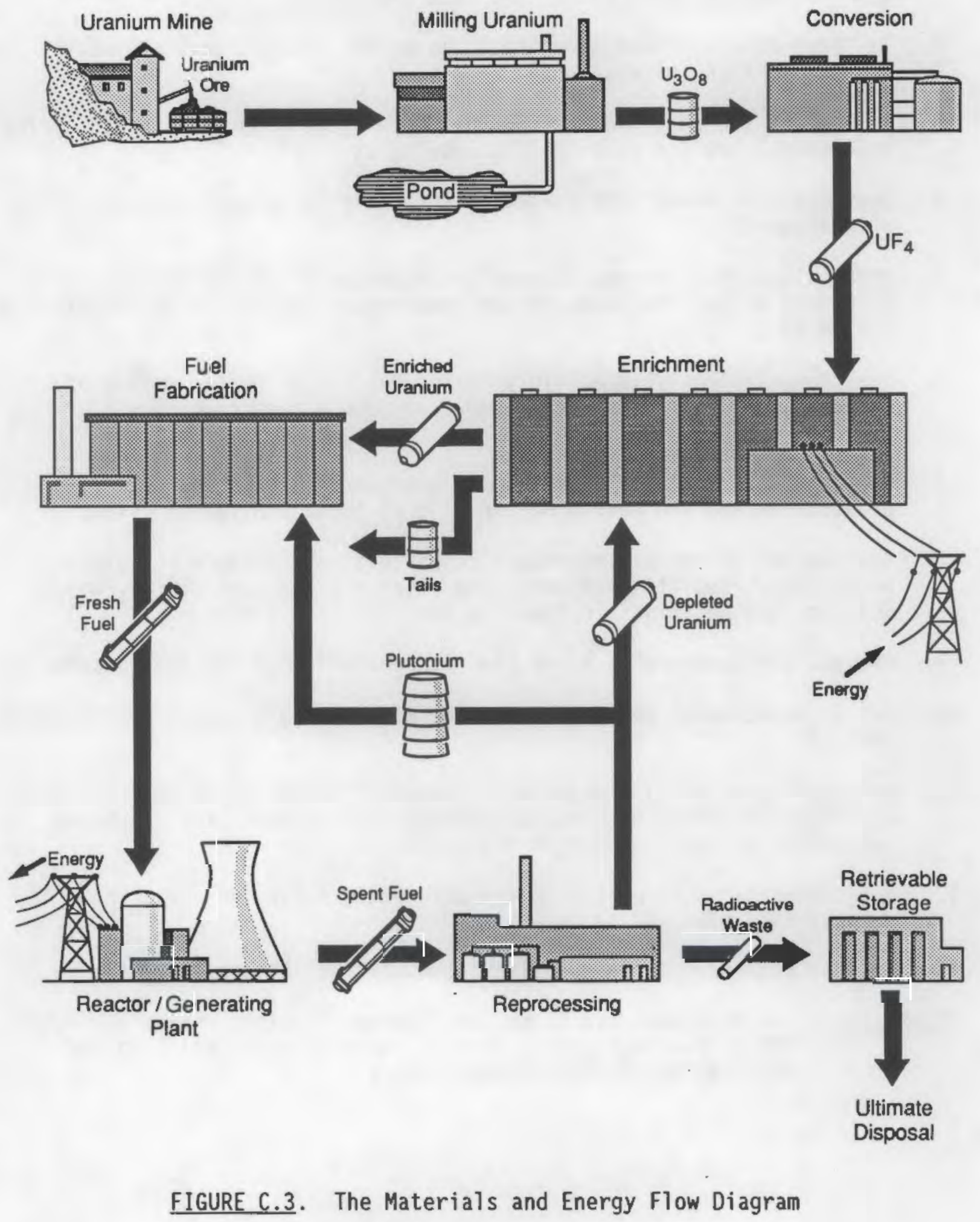


1. Does the risk analysis first state the health damage that may occur and then present the odds (i.e., the risk analysis)?

2. Is there enough information available on the factors that are most crucial to risk calculations?

3. If some of the data are missing but there are enough to approach a risk assessment, are the missing data labeled as such?

4. Does the risk analysis disclose forthrightly the points which are based on guesswork?

5. Are various risk factors allowed to assume a variety of numbers depending on uncertainties in the data and/or various interpretations of the data?

6. Does the risk analysis multiply its probabilities by the number of people exposed to produce the number of people predicted to suffer damage?

7. Does the risk analysis disclose the confidence limits for its projections and the method of arriving at those confidence limits?

8. Are considerations of individual sensitivities, exposure to multiple pesticides, cumulative effects, and effects other than cancer, birth defects, and mutations included in the risk analysis?

9. Are all data and processes of the risk analysis open to public scrutiny?

10. Has an independent peer review of the risk analysis been funded and made public?

11. Are questions of (a) involuntary exposure, (b) who bears the risk and who reaps the benefits, and (c) alternatives to pesticide use being considered alongside the risk analysis?

12. Are alternatives to pesticide use also being extensively analyzed for risk or lack of risk?

13. Are the processes of risk analysis and risk policy separate?

FIGURE C.4. The Risk Analysis Checklist (Source: National Research Council, 1989. Used with permission of the Northwest Coalition for Alternatives to Pesticides, 1985.) 
APPENDIX D

SUMMARY OF TSP COMMENTS AND BATTELLE RESPONSES 


\section{SUMMARY OF TSP COMMENTS AND BATTELLE RESPONSES}

Document Number PNL-7226 HEDR

Document Title Summary of Literature Review of Risk Communication

\begin{tabular}{|c|c|c|c|c|}
\hline $\begin{array}{l}\text { Comment } \\
\text { Number }\end{array}$ & Commenter & $\begin{array}{l}\text { Page, } \\
\text { Paragraph }\end{array}$ & Comment Summary & Resolution \\
\hline 1. & $\begin{array}{l}\text { Joe Stohr } \\
\text { (JS) }\end{array}$ & $\begin{array}{l}\text { Pages } \\
21-22\end{array}$ & $\begin{array}{l}\text { The discussion about reasons for early informa- } \\
\text { tion releases does not point out the need to make } \\
\text { the public a close partner in the research } \\
\text { project. }\end{array}$ & Addition made on page 22 . \\
\hline 2. & JS & $\begin{array}{l}\text { Pages } \\
21-22\end{array}$ & $\begin{array}{l}\text { Access to research information is beneficial not } \\
\text { only to provide information to the public, but to } \\
\text { also allow for their involvement and input to the } \\
\text { process. }\end{array}$ & Addition made on page 22 . \\
\hline 3. & JS & $\begin{array}{l}\text { Page } 26, \\
\text { para. } 3\end{array}$ & Remove "be" from the 4 th line. & Change was made. \\
\hline 4. & $\begin{array}{l}\text { Genevieve } \\
\text { Roessler } \\
\text { (GSR) }\end{array}$ & & $\begin{array}{l}\text { A more positive approach might be to ask "how } \\
\text { might this affect you?" rather than discussing } \\
\text { the "risk, "especially if it is with negative } \\
\text { exponent numbers. }\end{array}$ & NA \\
\hline 5. & GSR & & $\begin{array}{l}\text { There should not be undue concern about how the } \\
\text { communication will be carried out. We need to } \\
\text { agree first on the message. }\end{array}$ & $\begin{array}{l}\text { NA - Message and process of com- } \\
\text { municating it are both important. }\end{array}$ \\
\hline 6. & GSR & & $\begin{array}{l}\text { The National Research Council document (1989) } \\
\text { should be made available to all TSP members. }\end{array}$ & $\begin{array}{l}\text { NA - Publisher information is pro- } \\
\text { vided as part of citation. }\end{array}$ \\
\hline 7. & GSR & $\begin{array}{l}\text { Page } 15, \\
\text { last para. }\end{array}$ & $\begin{array}{l}\text { The packet must be flexible enough for the } \\
\text { speaker to use his/her own style and perspective. }\end{array}$ & True; NA \\
\hline$N A=N_{0}$ & action. & & & \\
\hline
\end{tabular}


SUMMARY OF TSP COMMENTS AND BATTELLE RESPONSES

Document Number PNL-7226 HEDR

Document Title Summary of Literature Review of Risk Communication

\begin{tabular}{|c|c|c|c|c|}
\hline $\begin{array}{l}\text { Comment } \\
\text { Number }\end{array}$ & Commenter & $\begin{array}{c}\text { Page, } \\
\text { Paragraph }\end{array}$ & Comment Summary & Resolution \\
\hline 8. & GSR & $\begin{array}{l}\text { Page. } 16, \\
\text { para. } 2\end{array}$ & $\begin{array}{l}\text { A combination of prepared materials and some that } \\
\text { the individual wants to use will work the best } \\
\text { for most speakers. }\end{array}$ & True; NA \\
\hline 9. & GSR & $\begin{array}{l}\text { Page } 16, \\
\text { para. } 3\end{array}$ & $\begin{array}{l}\text { Speakers working together on any presentation } \\
\text { must present the same message. }\end{array}$ & True; NA \\
\hline 10. & GSR & $\begin{array}{l}\text { Page } 17 \\
\text { para. } 2, \\
\text { line } 4\end{array}$ & $\begin{array}{l}\text { Eventually, } 1 \text { will need more information as to } \\
\text { what the facilitator or the promoter does. }\end{array}$ & $\begin{array}{l}\text { NA - That information was provided } \\
\text { verbally to the TSP before July } \\
1990 \text {. }\end{array}$ \\
\hline 11 . & GSR & $\begin{array}{l}\text { Page } 17 \\
\text { para. } 3\end{array}$ & $\begin{array}{l}\text { Best group (classroom) approach: 1) short TSP } \\
\text { presentation, 2) much time for audience/pre- } \\
\text { senters interaction 3) TSP wrap-up. }\end{array}$ & NA - TSP decision. \\
\hline 12. & GSR & Page 23 & $\begin{array}{l}\text { This will be the most difficult part to convey. } \\
\text { We can set a standard by factoring in the uncer- } \\
\text { tainty in the dose estimates. }\end{array}$ & Agree; NA \\
\hline 13. & $\begin{array}{l}\text { Glyn } \\
\text { Caldwel1 } \\
\text { (GGC) }\end{array}$ & $\begin{array}{l}\text { Page } 2, \\
\text { para. } 1 \\
\text { Iine } 2\end{array}$ & Colon needed after "include." & NA - Battelle style. \\
\hline 14. & GGC & $\begin{array}{l}\text { Page } 7 \\
\text { para. } 2 \\
\text { Tine } 1\end{array}$ & $\begin{array}{l}\text { A complementary objective for the HEDR Project is } \\
\text { to resolve problems and conflicts, primarily } \\
\text { public distrust. }\end{array}$ & $\begin{array}{l}\text { NA - Agree; however, this is a } \\
\text { broader objective than communi- } \\
\text { cation as used in context of this } \\
\text { report. }\end{array}$ \\
\hline$\overline{N A}=N_{0}$ & action. & & & \\
\hline
\end{tabular}


SUMMARY OF TSP COMMENTS AND BATTELLE RESPONSES

Document Number PNL-7226 HEDR

Document Title Summary of Literature Review of Risk Communication

\begin{tabular}{|c|c|c|c|c|}
\hline $\begin{array}{l}\text { Comment } \\
\text { Number }\end{array}$ & Commenter & $\begin{array}{c}\text { Page, } \\
\text { Paragraph }\end{array}$ & Comment Summary & Resolution \\
\hline 15. & GGC & $\begin{array}{l}\text { Page } 10 \text {, } \\
\text { para. } 5\end{array}$ & $\begin{array}{l}\text { What opportunities will there be for public par- } \\
\text { ticipation, comment, or input? }\end{array}$ & $\begin{array}{l}\text { NA - Seg audience analysis } \\
\text { report }(\hat{j}) \text { and Foreword. }\end{array}$ \\
\hline 16. & GGC & $\begin{array}{l}\text { Page 11, } \\
\text { para. } 1\end{array}$ & $\begin{array}{l}\text { Effectiveness of the TSP depends on the perceived } \\
\text { degree of openness to public concerns. }\end{array}$ & True; NA \\
\hline 17. & GGC & $\begin{array}{l}\text { Page 17, } \\
\text { para. 3, } \\
\text { ine 11 }\end{array}$ & Shouldn't "is" be "are"? & Sentence was reworded. \\
\hline 18. & $\begin{array}{l}\text { Mary Lou } \\
\text { Blazek } \\
\text { (MLB) }\end{array}$ & $\begin{array}{l}\text { Page 1, } \\
\text { para. } 3\end{array}$ & Delete "political," replace with "environmental." & $\begin{array}{l}\text { Deleted "political"; however, } \\
\text { replaced with "public interest } \\
\text { groups." }\end{array}$ \\
\hline 19. & MLB & Page 7 & $\begin{array}{l}\text { Credibility issues have plagued the Project from } \\
\text { the beginning. It is clear that another primary } \\
\text { TSP objective is to resolve conflicts and } \\
\text { problems. }\end{array}$ & $\begin{array}{l}\text { MA - True, but beyond the scope of } \\
\text { this document. }\end{array}$ \\
\hline 20. & MLB & & $\begin{array}{l}\text { This report did not complete the requirements of } \\
\text { Directive } \mathrm{B} 9-7 \text {. Costs should be estimated and } \\
\text { provided to the TSP as soon as possible. }\end{array}$ & $\begin{array}{l}\text { NA - Report was not intended to } \\
\text { address all aspects of Directive } \\
\text { B9-7. See Foreword. }\end{array}$ \\
\hline $\begin{array}{ll}N A= & \text { No } \\
(\text { a) } & \text { Hol } \\
& \text { Reco }\end{array}$ & $\begin{array}{l}\text { action. } \\
\text { mes, C. W. } \\
\text { mistruction Prd }\end{array}$ & $\begin{array}{l}\text { 1990. A Pre } \\
\text { ject. PNL }-723\end{array}$ & $\begin{array}{l}\text { iminary Examination of Audience-Related Communications } \\
\text { HEDR, Pacific Northwest Laboratory, Richland, Was }\end{array}$ & $\begin{array}{l}\text { ssues: Hanford Environmental Dose } \\
\text { hington. }\end{array}$ \\
\hline
\end{tabular}




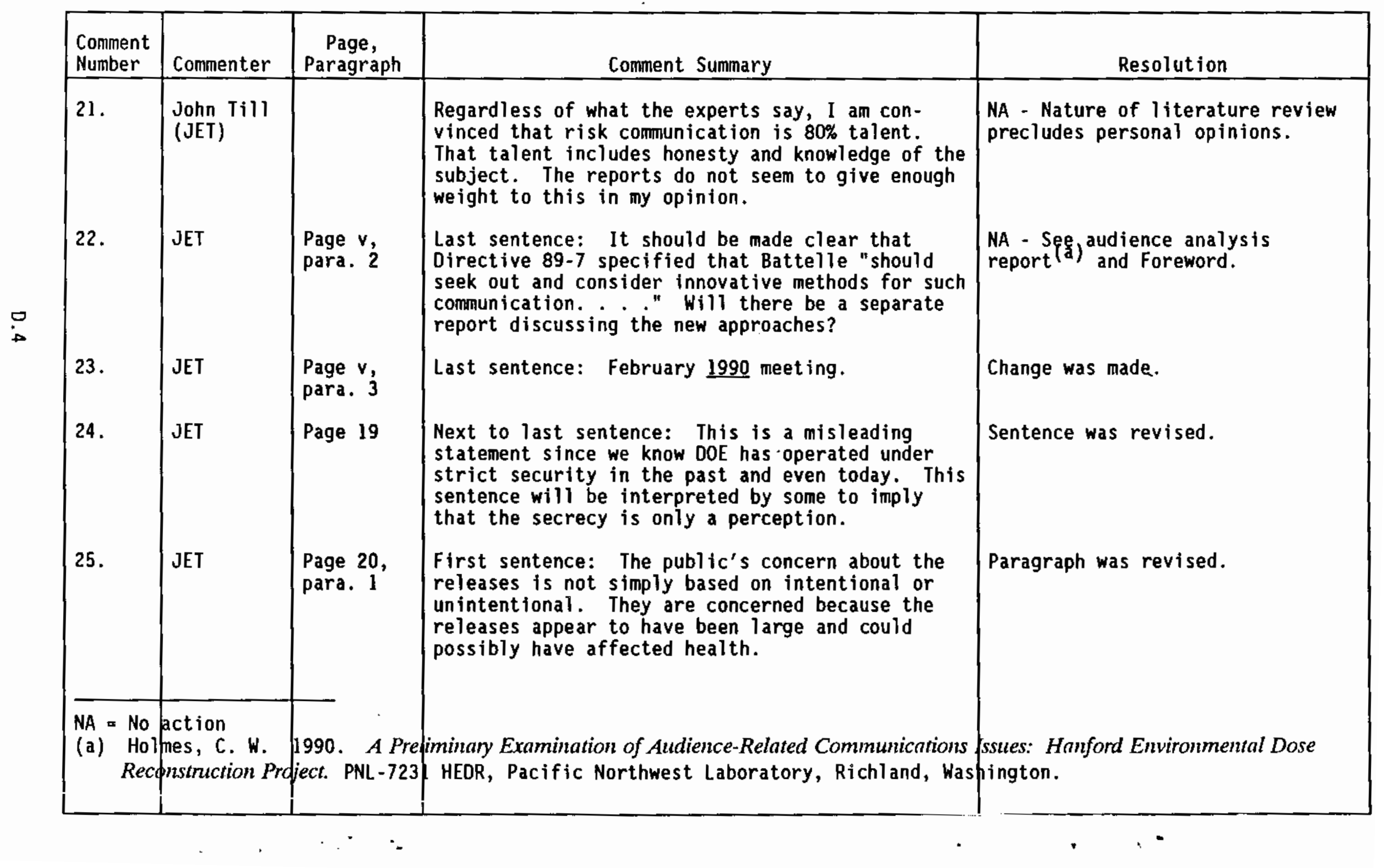


SUMMARY OF TSP COMMENTS AND BATTELLE RESPONSES

Document Number PNL-7226 HEDR

Document Title Sumary of Literature Review of Risk Communication

\begin{tabular}{|c|c|c|c|c|}
\hline $\begin{array}{l}\text { Comment } \\
\text { Number }\end{array}$ & Commenter & $\begin{array}{c}\text { Page, } \\
\text { Paragraph } \\
\end{array}$ & Comment Summary & Resolution \\
\hline 26. & JET & $\begin{array}{l}\text { Page } 20, \\
\text { para. 2, } \\
\text { lines } 6-9\end{array}$ & $\begin{array}{l}\text { A person who does not honestly believe something } \\
\text { they are saying should not be trying to convince } \\
\text { the pubiic of anything. It is all right to make } \\
\text { statements understandable, but not just so the } \\
\text { public can "feel" they have been heard. }\end{array}$ & $\begin{array}{l}\text { NA - Text does not suggest telling } \\
\text { public something you don't believe } \\
\text { is true. Rather, the approach } \\
\text { focuses on acknowledging the pub- } \\
\text { lic's somet imes strong emotions } \\
\text { rather than ignoring or down- } \\
\text { playing them. }\end{array}$ \\
\hline 27. & JET & $\begin{array}{l}\text { Page 21, } \\
\text { para. 2-4 }\end{array}$ & $\begin{array}{l}\text { This approach seems negative rather than posi- } \\
\text { tive. I believe we are being overly cautious in } \\
\text { our concern about release of information. I also } \\
\text { bel ieve the public respects our job as scient ists } \\
\text { to give them the best answer. }\end{array}$ & $\begin{array}{l}\text { NA - Caution and inquisitiveness } \\
\text { are characteristics of good } \\
\text { scientists, especialiy if we are } \\
\text { accountable for the "best answer." }\end{array}$ \\
\hline 28. & JET & $\begin{array}{l}\text { Page } 21, \\
\text { Past para. }\end{array}$ & $\begin{array}{l}\text { The desire for openness and the need to add } \\
\text { interpretation and meaning need not be mutually } \\
\text { exclusive. The TSP should be prepared to help } \\
\text { the public understand the meaning of results when } \\
\text { asked. }\end{array}$ & Agree; NA \\
\hline 29. & JET & & The report needs a conclusion. & $\begin{array}{l}\text { NA - Section } 4.0 \text { is considered a } \\
\text { conclusion. Aiso see Foreword. }\end{array}$ \\
\hline 30. & JET & & $\begin{array}{l}\text { You should consider adding to this report the } \\
\text { section on your recommendations for new } \\
\text { approaches to risk communication, so the document } \\
\text { will then address all of Directive } 89-7 \text {. }\end{array}$ & $\begin{array}{l}\text { NA - Recommendations were not } \\
\text { intended as part of this } \\
\text { literature review, see audience } \\
\text { analysis report }{ }^{\text {a }} \text { - and Foreword. }\end{array}$ \\
\hline $\begin{aligned} \mathrm{NA}= & \mathrm{No} \\
(\mathrm{a}) & \mathrm{Hol} \\
& \operatorname{Rec} \phi\end{aligned}$ & $\begin{array}{l}\text { action. } \\
\text { mes, C. W. } \\
\text { nnstruction Prd }\end{array}$ & $\begin{array}{l}\text { 1990. A Pre } \\
\text { ject. PNL }-723\end{array}$ & $\begin{array}{l}\text { iminary Examination of Audience-Related Communications } \\
\text { HEDR, Pacific Northwest Laboratory, Richland, Was }\end{array}$ & $\begin{array}{l}\text { ssues: Hanford Environmental Dose } \\
\text { ington. }\end{array}$ \\
\hline
\end{tabular}




\section{DISTRIBUTION}

No. of

Copies

OFFSITE

18 Technical Steering Panel

D. S. 8arth

University of Nevada

4505 Maryl and Parkway

Las Vegas, NV 89154

H. A. Bishop

2503 Wedgewood Court SE

01 ympia, WA 98501

M. L. Blazek

Oregon Department of Energy

625 Marion Street N.E.

Salem, OR 97310

G. G. Caldwell

Director

Tulsa City-County Health Dept

4616 East 15th Street

Tulsa, OK 74112

S. N. Davis

Dept. of Hydrology \& Water

Resources

Bldg. 11

University of Arizona

Tucson, AZ 85721

N. J. Germond

224 Iron Mountain B7vd.

Lake Ozwego, OR 97034

P. C. KTingeman

Civil Engineering Dept.

Oregon State University

Corvallis, OR 97331-2302
No. of

Copies

K. J. Kopecky

Fred Hutchinson Cancer

Research Center

1124 Columbia Street

Seattle, WA 98104

R. L. Morrill

Dept. of Geography

DP-10

University of Washington

Seattle, WA 98195

A. H. Murphy

C/o Climate Analyses Center

National Weather Service, NOAA

W/NMC51, WWB, Room 604

Washington, DC 20233

V. Nguyen

EWA, Inc.

133 lst Ave. N.

Minneapolis, MN 55401

D. W. Price

Agricultural Economics

Hulbert Hall Room 211

Washington State University

Pullman, WA 99164-6210

M. A. Robkin

Radiological Sciences SB-75

University of Washington

Seattle, WA 98195

G. S. Roess]er

Rt. 1, Box 139H

Elysian, MN 56028 
No. of

Copies

B. Shleien

2421 Homestead Drive

Silver Springs, MD 20902

A. P. Slickpoo, Sr.

P. 0. Box 331

809 Nez Perce Lane

Kamiah, ID $\mathbf{8 3 5 3 6}$

J. E. Till

Rt. 2 Box 122

Neeses, SC 29107

D. E. Walker, Jr.

P.0. Box 4147

Boulder, CO 80306

2 DOE Office of Scientific and Technical Information

Technical lnformation Center P.0. Box 62

Oak Ridge, TN 37830

18 K. Charlee

Office of Nuclear Waste Mgmt.

Department of Ecology

99 South Sound Center

Mai1 Stop PV-11

07ympia, WA 98504

J. Thomas, HEAL

325 S. Oak St.

Spokane, WA 99204
No. of

Copies

\section{DNSITE}

2 DOE Richland Operations

R. F. Brich, SED

A5- 55

M. W. Tiernan, SED

A5-55

37 Pacific Northwest Laboratory

S. J. Byram (5)

K6-66

J. M. Daer (10)

K6-89

W. A. Glass (6)

K4 -13

S. P. Gydesen

G. L. Harvey

P8-55

C. W. Holmes

$\mathrm{K} 1-55$

A. H. MclMakin

$K 6-66$

B. A. Napier

R. E. Rhoads

W. L. Templeton

$K 6-86$

K3-54

K6-64

(5) $A 1-65$

Publishing Coordinat ion $\mathrm{K} 1-1$

Records Center

$K 1-11$

Technical Library 